\title{
Experimental Investigation on the Evolution of Damage and Seepage Characteristics for Red Sandstone under Thermal-mechanical Coupling Conditions
}

Haopeng Jiang

Dalian Maritime University

Annan Jiang ( $\sim$ jiangannan@163.com )

Dalian Maritime University

Fengrui Zhang

DMU: Dalian Maritime University

\section{Research Article}

Keywords: Red sandstone, High temperature, Seepage characteristics, Statistical damage, Constitutive model

Posted Date: July 6th, 2021

DOI: https://doi.org/10.21203/rs.3.rs-365312/v1

License: (c) (1) This work is licensed under a Creative Commons Attribution 4.0 International License.

Read Full License

Version of Record: A version of this preprint was published at Environmental Earth Sciences on November 29th, 2021. See the published version at https://doi.org/10.1007/s12665-021-10121-x. 


\title{
Experimental investigation on the evolution of damage and seepage
}

\section{characteristics for red sandstone under thermal-mechanical coupling conditions}

\author{
Haopeng Jiang ${ }^{1}$, Annan Jiang ${ }^{1 *}$, Fengrui Zhang ${ }^{1}$
}

${ }^{1}$ Institute of Road and Bridge Engineering, Dalian Maritime University, Dalian 116026, China. Correspondence should be addressed to Annan Jiang*; jiangannan@163.com

Abstract: Rock masses in underground space usually experience the coupling of high-temperature field, stress field and seepage field, which gives them complex mechanical behavior and permeability characteristics. In order to study the mechanical properties and permeability characteristics of red sandstone under different temperature environments, a seepage test under high temperature and triaxial compression is carried out based on the RLW-2000 multi-field coupling tester. The results show that the plastic flow of red sandstone at the stress peak under the same temperature is more obvious with the increase of confining pressure. In addition, as the confining pressure gradient increases, the permeability decreases and the trend becomes slower. And the higher the operating temperature, the easier to produce seepage channels inside the rock sample. The development of fissures is rapidly developed under the effect of temperature, so the seepage channels are widened and increased, and the permeability is greatly increased. The constitutive model of rock statistical damage considering the interaction of high temperature and osmotic pressure was constructed based on the experimental data and combining theoretical methods to reveal the characteristics of permeability evolution induced by thermal damage of rocks. The research results can be used as a reference for monitoring rock stability during geological engineering projects involving thermal-seepage-stress coupling conditions.

Keywords: Red sandstone, High temperature, Seepage characteristics, Statistical damage, Constitutive model

\section{Introduction}

At present, more and more geotechnical engineering projects are developing and exploring deep underground, and their environment is becoming more and more complex. In order to ensure the stability and safety of geotechnical engineering, the permeability characteristics of rocks under different working conditions have become an important research topic in the field of rock mechanics (Zhao., 2016; Yao et al., 2015; Chen et al., 2018b; Chen et al., 2014). Such as temperature and fluids during deep geothermal extraction can also affect the permeability of the surrounding rock in the drilling well wall (Schulze et al., 2001; Wang et al., 2013; Wang et al., 2015). Meanwhile, there are also few reports on the permeability test of the full stress-strain rock mass with the coupling of temperature and stress, and the study of the permeability evolution law during the gradual cracking 
process of the coupled temperature and stress also needs to be carried out. Therefore, it is necessary to reveal the variation law of permeability characteristics of geothermal pipeline surrounding rocks under deep mining geothermal environment.

In recent years, many researchers have studied the stress-seepage coupling mechanism of different types of rocks during triaxial compression deformation under confining pressure and explained the relationship between rock permeability and total stress-strain (Tanikawa et al., 2015; Liu et al., 2012; Zhu et al., 2016; Zhao et al., 2017; Oda et al., 2002). It is found that the permeability decreases with the increase of confining pressure and increases with the osmotic pressure (Meng et al., 2019; Gräf et al., 2013; Sun et al., 2019). Chaki et al. (2008) measured the porosity, permeability, velocity and attenuation of ultrasonic waves in granite exposed to different high temperatures (up to $600^{\circ} \mathrm{C}$ ), and noted that ultrasonic velocity is a sensitive parameter that can provide information on the state of the rock. Li et al. (2017) studied the relationship between the seepage flow rate of rock fractures and temperature, and the results showed that the rock fracture opening and seepage flow rate gradually increased with the thermal temperature. Zhang et al. (2019) found that the permeability of granite after losing its bearing capacity showed an exponential upward trend as the confining pressure decreased. After heat treatment, the permeability under the triaxial loading process first decreases in the micro-crack closure area, while it is almost constant in the elastic area, and then increases sharply in the crack propagation area (Chen et al. 2014). With the existing materials and indoor environment, it is difficult to restore the high temperature environment of the rock mass. At this stage, most of the rock mechanics tests involving temperature are studied in combination with hydraulic conditions after temperature treatment. Heiland (2003) used sandstone as the research object and studied the permeability characteristics of sandstone during deformation and failure and the evolution of rock permeability before and after failure. Wang et al. (2014) used laboratory tests to study the hydraulic characteristics of altered rocks under different confining pressures. Rostovanyi (2013) studied clay rock sensitivity to temperature field, seepage field and stress field. Yang et al. (2017) analyzed the influence of temperature $\left(25-800^{\circ} \mathrm{C}\right)$ on the physical properties, mechanical properties and permeability of sandstone. The critical temperature $\left(T_{\mathrm{c}}\right)$ of sandstone mechanics and permeability behavior change was determined to be $400-500^{\circ} \mathrm{C}$.

Based on the above research results, there are few reports on the study of rock mechanics and seepage characteristics in the process of gradual fracture under different temperatures. In fact, the same rock has different mechanical properties and permeability characteristics under different working conditions. Thus, the seepage experiment of red sandstone under the coupling action of thermal-hydro-mechanical field was carried out in this paper, and the effects of different temperatures, different seepage pressure and confining pressure on the 
permeability during the gradual fracturing of red sandstone were studied. Based on the experimental data, a constitutive model of rock statistical damage considering the interaction of high temperature and seepage pressure is constructed and verified the rationality of the model. And combining theoretical methods to reveal the characteristics of permeability evolution induced by thermal damage of rocks. The research results can provide a certain reference basis for the construction and long-term stability of geotechnical engineering projects involving thermal-seepage-stress coupling.

\section{Test principle and scheme}

\subsection{Sample preparation}

The rock blocks used in the experimental test were sampled from the sandstone of a tunnel project in Hunan, China. The rock samples comprised reddish-brown sandstone. According to the test procedures of the International Society for Rock Mechanics (ISRM), the red sandstone block was drilled, cored, and grounded to obtain a standard cylindrical sample with a size of $\Phi 50 \mathrm{~mm} \times 100 \mathrm{~mm}$ (Fig. 1). The flatness of the end face was $\pm 0.02 \mathrm{~mm}$. The specimens with macroscopic damage or obvious cracks were removed before testing to eliminate the influence of pre-fractured samples on the test.

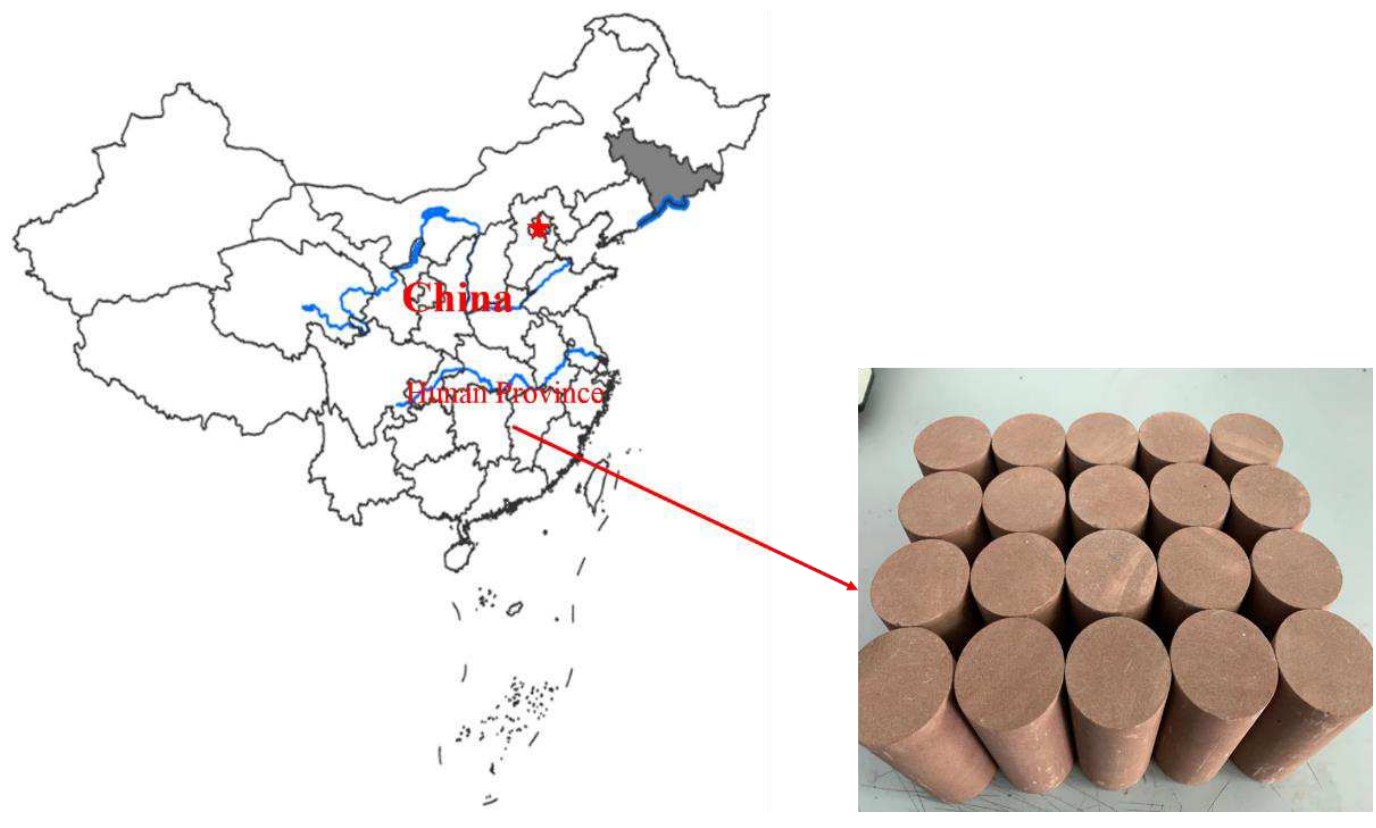

Fig. 1. Red sandstone specimen

\subsection{Test equipment}

The test was carried out using an RLW-2000 multifield coupled triaxial instrument, developed jointly by Dalian Maritime University and Changchun Chaoyang Testing Machine Factory (Fig. 2). This instrument is suitable for the temperature-mechanical coupling and conventional mechanical testing of lithified geological materials. The RLW-2000 system comprises an axial pressure, confining pressure, and seepage system, and other parts, as well as special displacement and radial deformation sensors. The maximum axial load was $2000 \mathrm{kN}$, and the measurement and control accuracy was within $0.01 \%$. When the confining pressure reached $80 \mathrm{MPa}$, the 
osmotic pressure reached $50 \mathrm{MPa}$. The maximum temperature, controlled by a microcomputer, was $200^{\circ} \mathrm{C}$, and the control accuracy was $2 \%$.

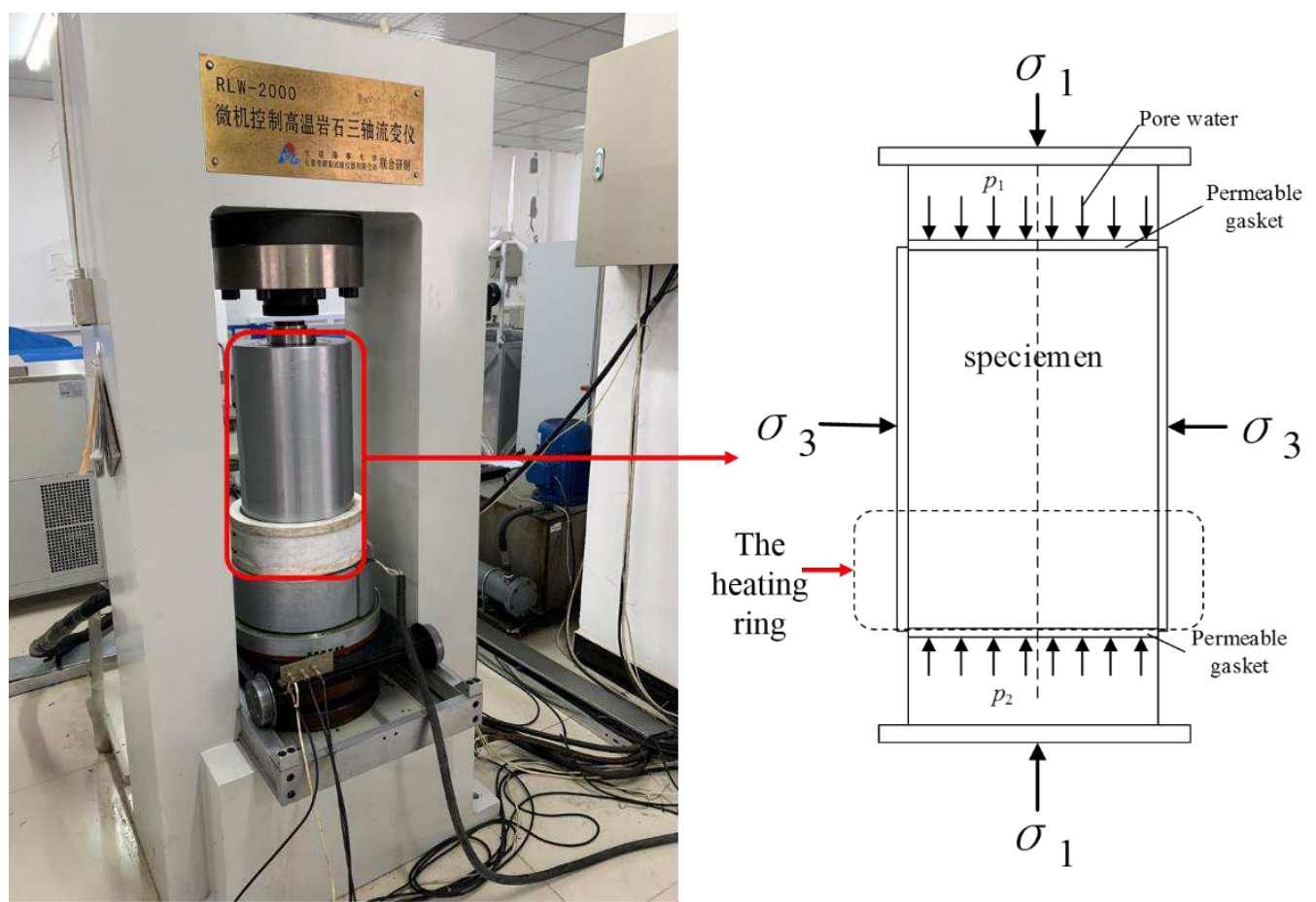

Fig. 2. RLW-2000 multi-field coupling rock triaxial instrument and seepage device

\subsection{Test principle}

In order to study the permeability changes of red sandstone under different temperatures, osmotic pressure, and triaxial compression conditions. In this test, the steady-state method and the transient method are used to determine the permeability of red sandstone. And combined with theoretical methods to reveal the evolution mechanism of permeability in the process of rock gradual cracking.

(1) Assuming that the sample is a uniform continuum material, the permeability characteristics are in accordance with Darcy's law (Chen et al., 2017b; Yang et al., 2015; Eberhardt et al., 1998). The expression used to test the permeability of the sample is as follows:

$$
k=\frac{\mu L \Delta Q}{A \Delta P \Delta t}
$$

Where $k$ is the permeability of the sandstone sample within $\Delta t\left(\mathrm{~m}^{2}\right) . \mu$ is the fluid (water) viscosity coefficient, taking $\mu=1 \times 10^{-3} \mathrm{~Pa} \cdot \mathrm{s}$ ( Water temperature $20^{\circ} \mathrm{C}$ ). $\Delta Q$ is the volume of water flowing through the red sandstone sample within $\Delta t\left(\mathrm{~m}^{3}\right) . L$ is the seepage length of the water flow, that is, the height of the sample in the test, $L=0.1 \mathrm{~m} . A$ is the cross-sectional area of the sample $\left(\mathrm{m}^{2}\right) . \Delta P$ is the osmotic pressure difference between the upper and lower ends of the red sandstone sample $\left(\Delta P=P_{1}-P_{2}\right) . P_{1}$ and $P_{2}$ are the upstream and downstream pressures of the seepage respectively. The following $\Delta P$ is consistent with this (Pa). $\Delta t$ is the interval time between recording points (s). 
(2) The basic principle of the transient method is:

Apply an equal constant water pressure on the upper and lower ends of the rock to form an initial pressure field in the core. A pulse water pressure is applied by the downstream flow pump, and a bottom-up seepage flow is generated in the core under the action of the pressure difference. After that, the upstream pressure $P_{1}$ will gradually decay, and the downstream pressure $P_{2}$ will gradually rise until the pressure balance is reached. The permeability is calculated using the attenuation law of the upstream and downstream pressure difference. According to Brace et al., (1968) introduction to the principles and methods of the transient method, the interpretation formula for solving the permeability is:

$$
\begin{aligned}
& \Delta P_{t}=\left(\Delta P_{0}\right) e^{-\alpha t} \\
& k=\frac{\alpha \mu L\left(C_{1} C_{2}\right)}{A\left(C_{1}+C_{2}\right)}
\end{aligned}
$$

Where $k$ is the core permeability $\left(\mathrm{m}^{2}\right) . \Delta P_{t}$ is the measured value of upstream and downstream pressure difference (MPa). $\Delta P_{0}$ is the initial pressure difference (MPa). $t$ is the elapsed time (s). $C_{1}$ and $C_{2}$ are the water capacity of the upstream and downstream pressure vessels respectively. The water capacity $C_{1}$ of the upstream pressure vessel is defined as: $C_{1}=d v_{1} / d p_{1}$. The order of magnitude is $10^{-14} \mathrm{~m}^{3} / \mathrm{Pa} . C_{2}$ is the same.

From the semi-logarithmic differential pressure-time curve (as shown in Fig. 3), it can be seen that the permeability $k$ can be obtained by substituting the slope $\alpha$ into equation (3). In the actual measurement, a measurement can be completed when the pressure difference decays to about $50 \%$ of the initial stage. Therefore, the time required for the pressure difference to decay $50 \%$ is called the pressure difference decay half-life, which is represented by $t_{50}$ (Ranjith et al., 2012; Shao et al., 2015).

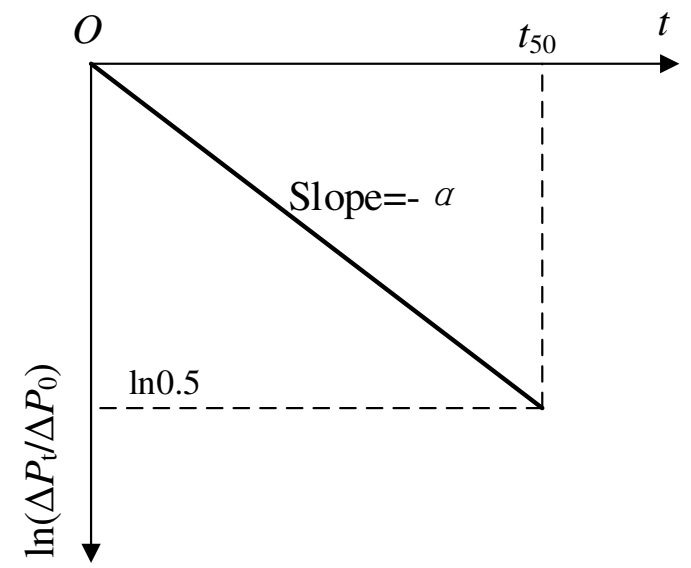

\subsection{Test procedure}

Fig. 3. Semi-logarithmic differential pressure-time curve

The stratigraphic temperature will increase with the increase of excavation depth, and the ground temperature gradient is $30^{\circ} \mathrm{C} / \mathrm{km} \sim 50^{\circ} \mathrm{C} / \mathrm{km}$, and the local abnormal area can reach $80^{\circ} \mathrm{C} / \mathrm{km}$ (Xie et al., 2005; Walch et al., 2021). Meanwhile, for a geothermal project with a mining depth of $2 \mathrm{~km}$, the corresponding temperature is $60^{\circ} \mathrm{C}$ 
to $100^{\circ} \mathrm{C}$. Since this test is a seepage test under the action of thermal-mechanical coupling and the fluid medium is water. When the temperature exceeds $100^{\circ} \mathrm{C}$, the water will evaporate into water vapor and generate air pressure, which will affect the permeability of this test. Therefore, the maximum temperature of the triaxial pressure chamber in this test is set to $90^{\circ} \mathrm{C}$. Meanwhile, the highest ground stress for a geothermal pipeline with an excavation depth of $2 \mathrm{~km}$ is $30 \mathrm{MPa}$. (Wang et al., 2014). In order to test the effect of different temperatures and different confining pressures on the permeability of red sandstone, the temperature of this test program is selected as $20^{\circ} \mathrm{C}, 50^{\circ} \mathrm{C}, 70^{\circ} \mathrm{C}$ and $90^{\circ} \mathrm{C}$, and the confining pressure is selected as $10 \mathrm{MPa}, 20 \mathrm{MPa}$ and $30 \mathrm{MPa}$. Because the pressure of permeated water vapor increases with the temperature, and the saturated vapor pressure of water at $90{ }^{\circ} \mathrm{C}$ is $0.070117 \mathrm{MPa}$. In order to ensure that the test is not disturbed by steam, the lowest pressure upstream and downstream of the seepage flow is set to $0.1 \mathrm{MPa}$. The highest osmotic pressure difference is $5 \mathrm{MPa}$. When the steady-state method is used to determine the permeability, the upstream and downstream hydraulic pressure difference $\Delta P$ is $1,2,3,4,5 \mathrm{MPa}$. When the transient method is used to determine the permeability, the equilibrium pressure of the upstream and downstream of the seepage is $5 \mathrm{MPa}$, the pressure pulse is $1 \mathrm{MPa}$, and the downstream pressure reduction method of the seepage is adopted. In order to eliminate as much as possible the influence of rock heterogeneity on the experimental results, each set of tests in this test was designed as three specimens, and the stress-strain curves and permeability values were taken as the middle value of three specimens (Yang et al. 2019). The test steps are:

(1) After the oil flushing in the pressure chamber is completed, in order to prevent the saturated water inside the rock sample from escaping due to heating, the upstream and downstream pressure of the seepage is maintained at $0.5 \mathrm{MPa}$ and raise the temperature to the set value and wait for it to stabilize for 12 hours before proceeding to the next step.

(2) Apply the confining pressure to $10 \mathrm{MPa}$ at $1 \mathrm{MPa} / \mathrm{min}$ in a stress-controlled manner.

(3) Steady-state method:

Under the set confining pressure, the upstream of the seepage (the lower end of the rock sample) applies a seepage pressure $P_{1}=5.1 \mathrm{MPa}$, while maintaining the downstream of the seepage (the upper end of the rock sample) the seepage pressure $P_{2}=0.1 \mathrm{MPa}$. Under the action of osmotic pressure difference $\Delta \mathrm{P}=5 \mathrm{MPa}$, the osmotic pressure and time curve at the upstream of the seepage flow tends to be stable. This indicates that a stable seepage flow has occurred inside the rock sample. The downstream of the seepage flow is increased in the order of $0.1,1.1,2.1$, 3.1, 4.1 $\mathrm{MPa}$, and the permeability under different osmotic pressure differences is measured.

(4) Transient method: 
After the steady-state measurement is completed, the downstream $P_{2}$ of the seepage flow is increased to 5MPa, and $P_{1}=P_{2}=5 \mathrm{MPa}$ is maintained until the pressure and flow are stable. The pressure of the pore fluid inside the rock sample is balanced, the upstream pressure is kept constant, and pulse pressure is provided to the downstream of the seepage flow, and the water body penetrates under the action of the pressure difference. The upstream water pressure $P_{1}$ will gradually attenuate, and the downstream water pressure $P_{2}$ will gradually rise until the pressure at both ends is in a new balance, and then the upstream and downstream attenuation laws are used to calculate the permeability.

(5) Steps (3) and (4) were repeated for each of the set values of confining pressure. An axial displacement at a rate of $0.01 \mathrm{~mm} / \mathrm{min}$ was applied under each state of confining pressure, to investigate the permeation of the sample in the course of progressive fracturing under triaxial loading.

(6) Corresponding to different set temperatures, repeatedly set different confining pressure values and steps (3), (4) and (5).

(7) During the three-axis loading process, the testing machine automatically collects the stress, strain and water pressure stroke of the rock every $0.001 \mathrm{~h}$. Then, the water flow rate $\Delta Q$ permeating the sample within a period of time $\Delta t$ can be calculated, and substituting it into equation (1), the corresponding permeability $k$ of the sandstone during this period of time can be calculated.

\section{Test results and analysis}

\subsection{Analysis of full stress-strain curve and crack propagation law}

According to the differences in the state of the original micro-cracks in the rock under different stress levels, the full stress-strain curve of brittle rocks can generally be divided into 5 stages:

(1) Closed stage of rock primary fissure. (2) Linear elastic phase. (3) Crack growth stage. (4) Unsteady crack propagation. (5) Post-peak deformation and failure stage.

The stress thresholds corresponding to different stages correspond to crack closure stress $\sigma_{\mathrm{cc}}$, crack initiation stress $\sigma_{\mathrm{ci}}$, damage stress $\sigma_{\mathrm{cd}}$, peak stress $\sigma_{\mathrm{c}}$ and residual stress $\sigma_{\mathrm{cr}}$. The stress-strain-seepage relationship of rock samples at different temperatures and confining pressures is shown in Fig. 4. (The upper part is the stress-axial $\varepsilon_{1} /$ radial $\varepsilon_{3} /$ volume $\varepsilon_{\mathrm{v}}$ strain curve. The lower part is the relationship curve between upstream flow $P_{1}$, osmotic pressure difference $\Delta P$, permeability $k$ and axial strain $\varepsilon_{1}$ ). 


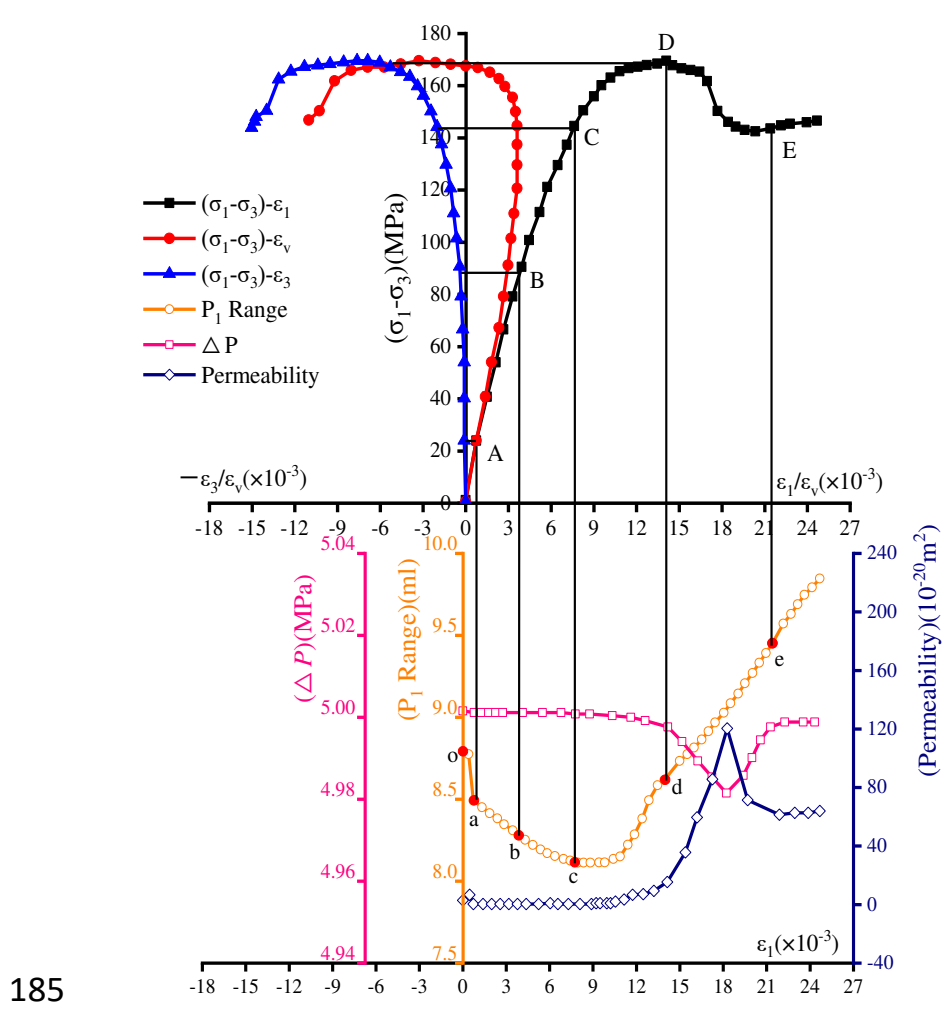

186

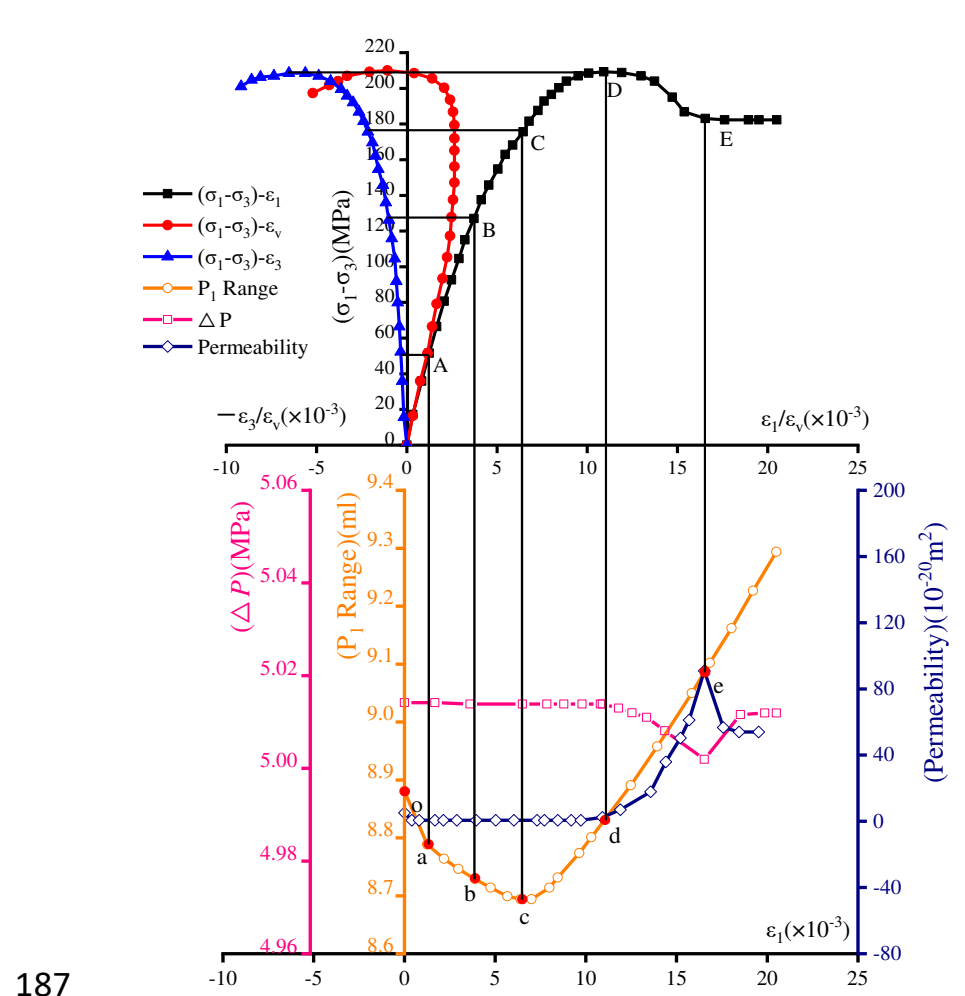

188

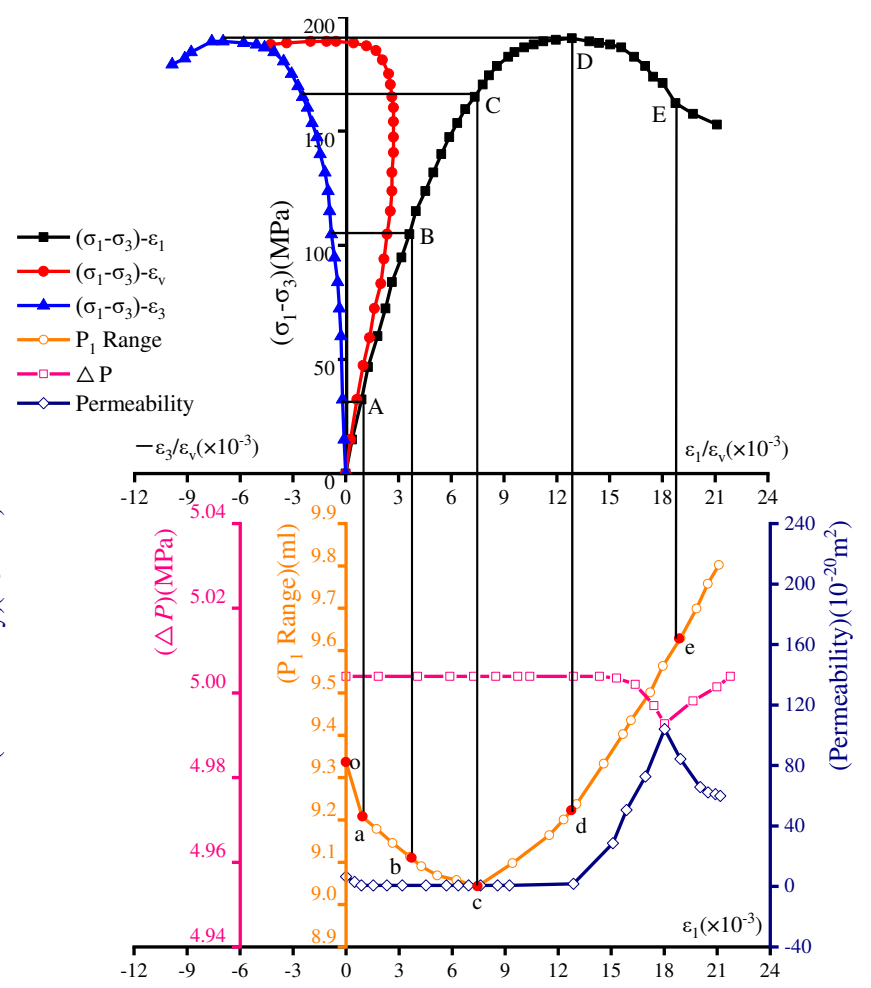

(b)

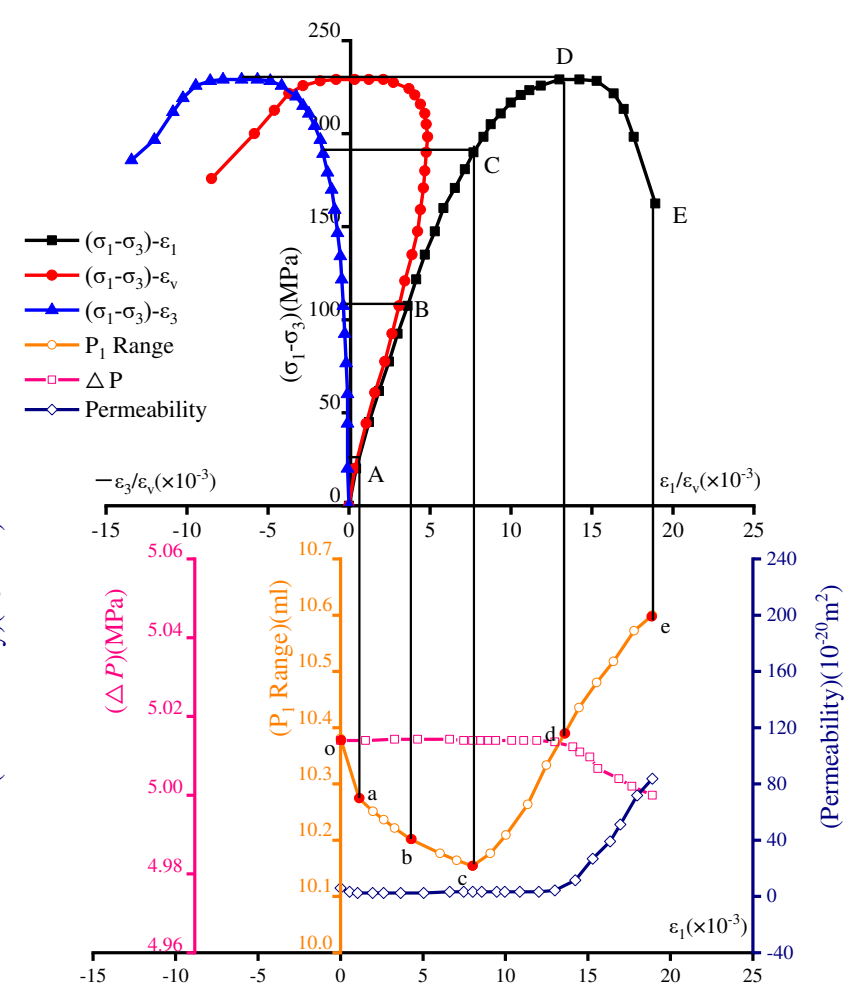

(d) 


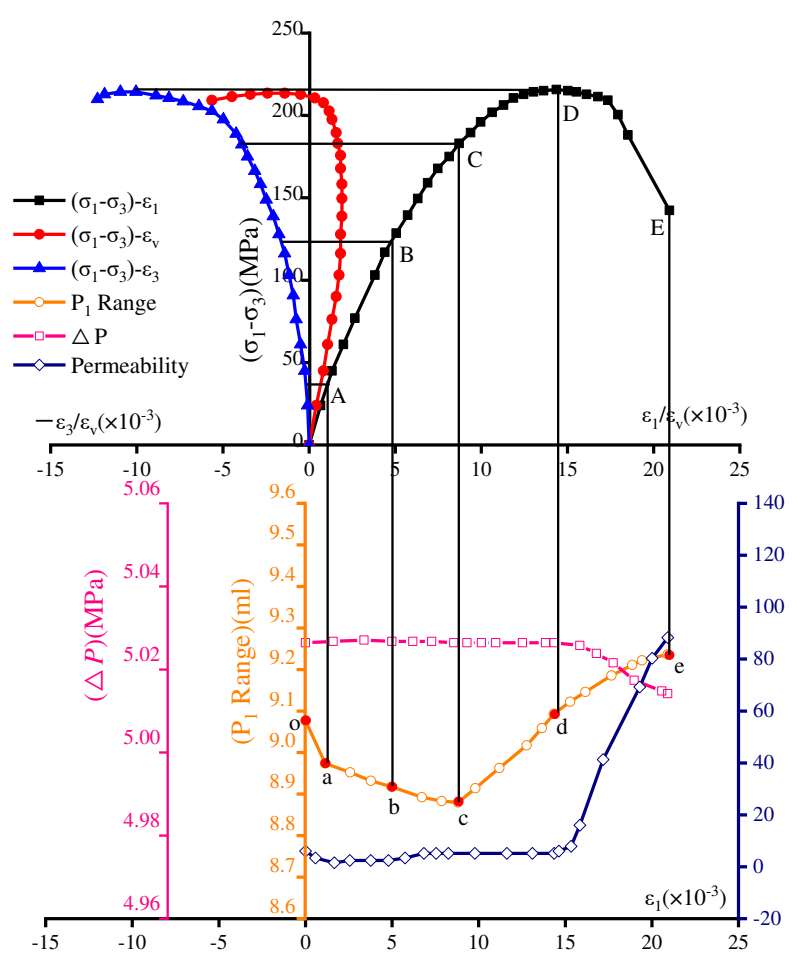

(e)

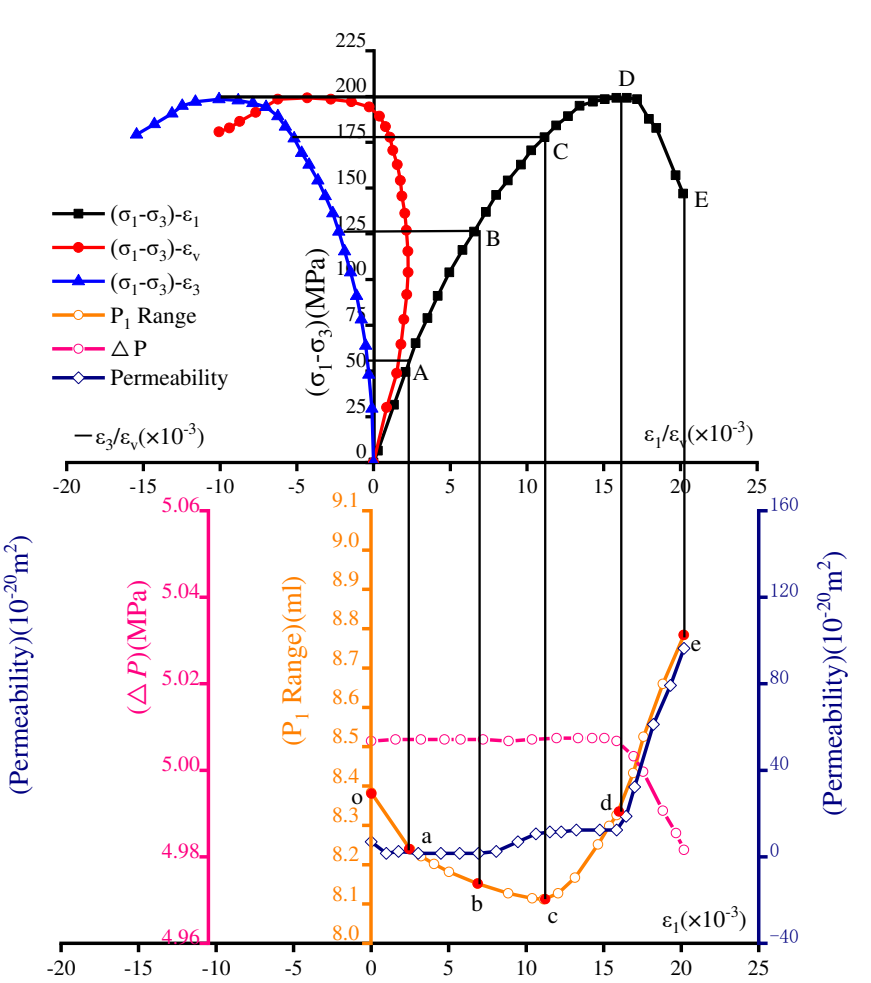

(f)

Fig. 4. The relationship curve of red sandstone stress-strain-seepage. (a) $90^{\circ} \mathrm{C}-30 \mathrm{MPa}, \triangle P=5 \mathrm{MPa}$ (b) $70^{\circ} \mathrm{C}-30 \mathrm{MPa}, \Delta P=5 \mathrm{MPa}(\mathrm{c}) 50^{\circ} \mathrm{C}$ $-30 \mathrm{MPa}, \Delta P=5 \mathrm{MPa}(\mathrm{d}) 20^{\circ} \mathrm{C}-30 \mathrm{MPa}, \Delta P=5 \mathrm{MPa}(\mathrm{e}) 20^{\circ} \mathrm{C}-20 \mathrm{MPa}, \Delta P=5 \mathrm{MPa}(\mathrm{f}) 20^{\circ} \mathrm{C}-10 \mathrm{MPa}, \Delta P=5 \mathrm{MPa}$

(1) First stage of seepage (o-a-b-c)

Point $O$ corresponds to the starting point of axial pressure loading, and the seepage curves o-a, a-b, and b-c respectively correspond to the original rock fracture compression and closure stage OA section, linear elastic stage $\mathrm{AB}$ section, and crack stable growth stage BC section. Point $a$ is determined by the inflection point of the initial sudden drop of the upstream flow $P_{1}$ range of the seepage, point $b$ is determined by the endpoint of the linear change of the $P_{1}$ range, and point $c$ is the position where the upstream flow is the smallest. Points $A, B$, and $C$ corresponding to $a, b$, and $c$ are the closing stress $\sigma_{\mathrm{cc}}$, the initiation stress $\sigma_{\mathrm{ci}}$, and the damage stress $\sigma_{\mathrm{cd}}$

As the original microfractures gradually became compressed and closed in section o-a, the volume of the pores and fissures within the specimen was reduced. Density increased, and the seepage channel was blocked, resulting in the rapid precipitation of fluid in the opposite direction, and a rapid weakening of the upstream flow. The stress-strain curve corresponding to section a-b was a linear elastic straight line: as the original fractures in the rock were further compacted, the upstream flow rate began to change linearly. In section b-c, the stress-strain curve begun to exhibit nonlinear change: the rock was in a compression state dominated by plastic deformation, and the fluid overflow rate at the bottom of the sample decreased. At this stage, the osmotic pressure difference, $\Delta P$, was relatively stable.

The first stage of seepage corresponds to the O-C segment of the stress-strain curve. In the AB stage, 
microfractures or microdefects in the rock are further closed and compacted, and the stress-strain curve in this stage is a straight line. Before point $\mathrm{C}$, the stress-axial strain curves can all be approximated as straight lines, but the stress-volume strain curves begin to show nonlinear variations. After point $\mathrm{C}$, the rock is in a compression stage dominated by plastic deformation and seepage channels begin to form. Martin et al. (1994) proposed to determine the characteristic strength of rocks by the inflection points of volumetric strain and crack volumetric strain versus axial strain curves, and was widely used in the analysis of results of conventional triaxial compression tests on brittle rocks. Thus, the characteristic strength value of point $\mathrm{C}$ is determined according to the inflection point of the relationship curves of rock stress-volume strain and stress-axial strain in this paper.

(2) Second stage of seepage (Section c-d)

The c-d stage of seepage corresponds to the unsteady crack propagation stage (CD section) in the stress-strain curve. Point $d$ corresponds to the peak stress in the stress-strain curve, where the corresponding permeability is the peak stress-permeability. The stress-strain relationship is nonlinear at this stage, when the microfractures inside the rock sample expand and penetrate rapidly, and the damage occurring inside it is gradually accumulated. The range of internal damage also starts to increase gradually. When the stress-strain curve reaches the point $D$, the strength of the rock sample reaches the peak, and the damage mode of the rock sample has changed from the microfracture of internal penetration to the obvious macroscopic damage at this time. As the stress increases, the strain rate increases, and the volumetric strain increases rapidly from a negative value to a positive value. At the same time, the corresponding flow chart shows that the sudden increase in the upstream flow of the rock sample in the c-d section indicates that the internal fractures are connected to each other, the seepage channel has been formed, and the fluid can quickly pass through the rock sample. At this time, the permeability tends to increase slightly. The reason is that the fluid is immersed into the rock to fill its pores and cracks and fewer fluids can pass through the rock. In addition, when the rock is under pressure and swelling, its internal fracture form intensifies, and plastic flow begins to appear. At the same time, the upstream flow rate of the rock sample maintains a steady increase, and the osmotic pressure difference $\Delta P$ also has a slow downward trend.

(3) Third stage of seepage (Section d-e)

The seepage d-e section corresponds to the post-peak deformation and failure stage (DE section), the stress-strain curve first develops gently and then decreases sharply. After a short period of plastic flow occurs in the rock sample under higher temperature and confining pressure, its internal micro-cracks intersect each other to form a macroscopic fracture surface. It then develops into a shear-slip failure surface, and gradually maintains stability after the bearing capacity decreases. At the same time, the upstream flow curve shows a linear growth in 
two sections, and the slope gradually increases. At this time, the osmotic pressure difference $\Delta P$ gradually decreases with the failure of the rock sample, and the permeability gradually increases. This is because the internal fractures of the rock sample grow rapidly at this stage, and seepage channels are continuously formed in new fractures. The formation of macroscopic fracture surfaces is the main reason for the rapid increase in permeability. Finally, under the combined action of axial stress and confining pressure, the internal fissures of the rock sample have a tendency to further close, and the permeability decreases after reaching the peak value and finally remains stable.

Based on the above analysis and Fig. 4 (a, b, c, d), it can be seen that the red sandstone undergoes a brittle-ductile transition under the condition of triaxial high confining pressure, and short-term plastic flow occurs before and after the peak stress, and its ductility increases. The effect of high-temperature heat damage makes this phenomenon even more prominent. At this time, the permeability has a tendency to increase rapidly after reaching a peak and then decrease and remain stable. According to Fig. 4 (d, e, f), under the same temperature, with the 
stress $\sigma_{\mathrm{cc}}$ is $32 \sim 34 \%$ of peak stress, initiation stress $\sigma_{\mathrm{ci}}$ is $58 \sim 61 \%$ of peak stress, damage stress $\sigma_{\mathrm{cd}}$ is $79 \sim 86 \%$ of peak stress, and residual stress $\sigma_{\mathrm{cr}}$ is $85 \sim 89 \%$ of peak stress. At the same time, the influence of high temperature on the seepage and mechanical properties of the rock cannot be ignored. The thermal effect reduces the strength of the cementation between the particles in the rock. The test results in this paper show that under the same confining pressure and osmotic pressure difference, with the increase of temperature, the ductility of red sandstone increases, the plastic flow is more obvious, and residual stress appears. The elastic modulus increases with the temperature, and the permeability of each stage also increases. This shows that the relatively low temperature has the effect of closing the cracks in the red sandstone, and the strength of the rock sample is enhanced. Higher temperature can quickly promote the development and penetration of micro-cracks inside the rock, deteriorating its mechanical properties. In addition, the increase in temperature will reduce the viscosity coefficient of water and the effective stress inside the rock. The corrosion and lubrication effect of high-temperature water on mineral particles is strengthened, and the cementation strength between the particles is reduced, which strengthens the softening and ductility of the rock (He et al., 2018; Yin et al., 2020). The interaction of high temperature and water enhances the micro-deterioration of the mechanical properties of red sandstone, while the loading of axial stress promotes the transformation from micro-degradation to macro-degradation.

\begin{tabular}{|c|c|c|c|c|c|c|c|c|c|c|c|c|}
\hline \multirow{2}{*}{$\begin{array}{c}\text { Rock sample } \\
\text { numbers }\end{array}$} & \multirow{2}{*}{$T /{ }^{\circ} \mathrm{C}$} & \multirow{2}{*}{$\sigma_{3} / \mathrm{MPa}$} & \multirow{2}{*}{$\Delta P / \mathrm{MPa}$} & \multirow{2}{*}{$E / \mathrm{GPa}$} & \multicolumn{3}{|c|}{ Permeability $(k) / 10^{-20} \mathrm{~m}^{2}$} & \multicolumn{5}{|c|}{ Stress level/MPa } \\
\hline & & & & & Initial value & Minimum & Maximum & $\sigma_{\mathrm{cc}}$ & $\sigma_{\mathrm{ci}}$ & $\sigma_{\mathrm{cd}}$ & $\sigma_{\mathrm{c}}$ & $\sigma_{\mathrm{cr}}$ \\
\hline a & 90 & 30 & 5 & 11.34 & 2.89 & 0.36 & 120.35 & 54.01 & 100.81 & 144.59 & 169.58 & 144.84 \\
\hline $\mathrm{b}$ & 70 & 30 & 5 & 11.94 & 6.47 & 0.66 & 104.07 & 60.18 & 114.95 & 159.57 & 190.68 & 171.07 \\
\hline $\mathrm{c}$ & 50 & 30 & 5 & 12.66 & 5.16 & 0.65 & 90.97 & 66.51 & 127.05 & 168.15 & 209.25 & 182.35 \\
\hline d & 20 & 30 & 5 & 20.44 & 6.06 & 2.45 & 83.74 & 77.50 & 135.00 & 180.83 & 229.17 & \\
\hline $\mathrm{e}$ & 20 & 20 & 5 & 15.01 & 6.06 & 1.55 & 88.26 & 76.99 & 128.56 & 175.05 & 215.73 & \\
\hline $\mathrm{f}$ & 20 & 10 & 5 & 14.21 & 6.97 & 1.55 & 96.39 & 65.23 & 116.13 & 170.61 & 199.28 & \\
\hline
\end{tabular}

The failure state of red sandstone under different temperatures and confining pressures are shown in Fig. 5.

The failure mode of the rock sample is the failure of a macroscopic single shear surface, and the fracture surface is relatively smooth. However, the edge damage is relatively high, and dense axial cracks develop near the shear zone. This is because the pressure in the axial direction is weakly suppressed by the confining stress at low confining stress and normal temperature, and the stress concentration area is easy to appear inside the rock sample during axial stress loading, so it leads to the damage of the rock sample along the main fracture surface of a single crack (Sun et al., 2019). In the high confining stress and temperature state, the rock sample was further compressed by the combined effect of high confining stress, temperature and axial stress, and the primary cracks were closed, resulting in a damage pattern formed by multiple crack stacking in the fracture surface area, 
indicating that the confining stress and temperature have obvious effects on the damage form of the rock sample. The failure angle of the rock sample (the complementary angle of the angle between the normal direction of the macroscopic main fracture surface and the axial compression direction) varies less with the increase of temperature.

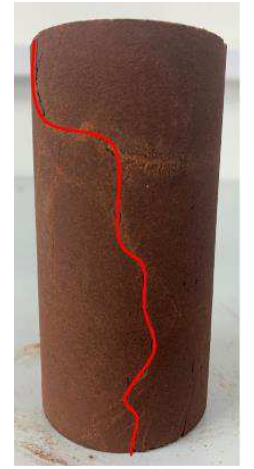

$20^{\circ} \mathrm{C}-10 \mathrm{MPa}$

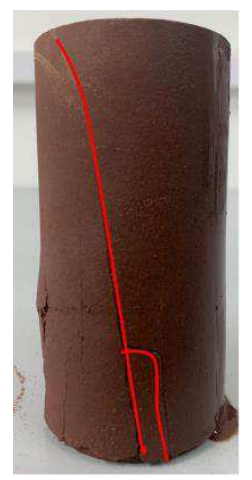

$50^{\circ} \mathrm{C}-30 \mathrm{MPa}$

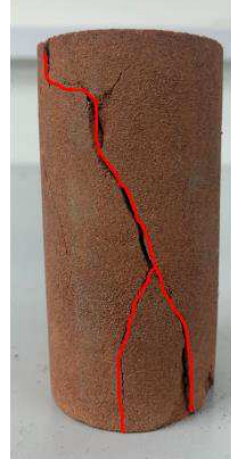

$20^{\circ} \mathrm{C}-20 \mathrm{MPa}$

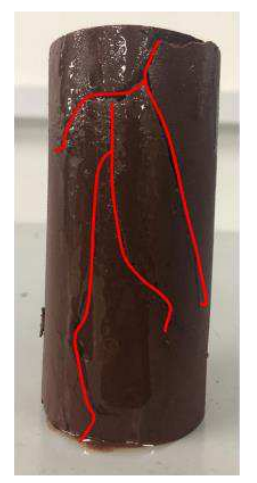

$70^{\circ} \mathrm{C}-30 \mathrm{MPa}$

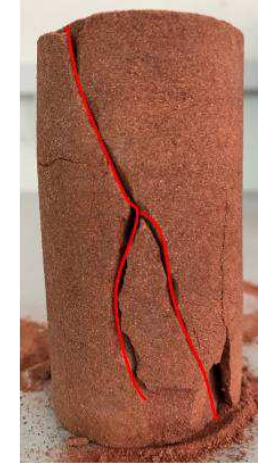

$20^{\circ} \mathrm{C}-30 \mathrm{MPa}$

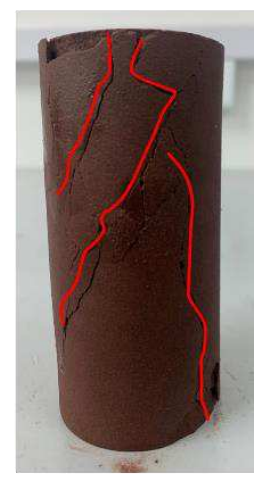

$90^{\circ} \mathrm{C}-30 \mathrm{MPa}$

Fig. 5. The macroscopic failure mode of red sandstone

\subsection{Permeability characteristics of red sandstone by the steady-state method}

3.2.1 Seepage characteristics of red sandstone under different seepage pressure difference and confining pressure

In order to study the seepage characteristics of red sandstone under different seepage pressure differences and confining pressure, this paper firstly uses the steady-state method to test the red sandstone. Fig. 6 shows the relationship between permeability and osmotic pressure difference under four temperature conditions. It is found that the permeability decreases with the increase of the osmotic pressure difference, indicating that this is related to the continuous effect of the confining pressure and the influence of temperature, and the gain of the osmotic pressure difference on the seepage velocity is weakened. Since this seepage test firstly fixes the osmotic pressure at the lower end of the rock sample and the osmotic pressure in the upper part of the sample is less than the osmotic pressure in the lower part, secondly the larger the osmotic pressure difference is, the smaller the average pore water pressure applied to the rock sample. Meanwhile, the larger its corresponding effective confining pressure, the smaller the hydraulic conductivity, when the permeability will be relatively weakened with the 
seepage pressure difference under the action of high confining pressure. Xiao et al. (2020) found that the permeability tends to decrease with a gradual increase in the seepage pressure difference, and the test was loaded with water pressure in a similar manner to this paper. Under the action of the osmotic pressure difference of $1 \mathrm{MPa}$ and the confining pressure of $10 \mathrm{Mpa}$, the permeability at different temperatures $\left(20^{\circ} \mathrm{C}, 50^{\circ} \mathrm{C}, 70^{\circ} \mathrm{C}, 90^{\circ} \mathrm{C}\right)$ is 41.25 $\times 10^{-20} \mathrm{~m}^{2}, 52.11 \times 10^{-20} \mathrm{~m}^{2}, 65.01 \times 10^{-20} \mathrm{~m}^{2}, 85.66 \times 10^{-20} \mathrm{~m}^{2}$, respectively. Meanwhile, it can be seen that when the osmotic pressure difference is $5 \mathrm{MPa}$ and the same confining pressure is applied, the permeability increases with the increase of the operating temperature. It shows that the temperature makes the micro-cracks or pores in the rock sample be further enlarged, the friction and cohesive force between the rock particles are reduced, the cross-section of the seepage channel is increased, and the water seepage is promoted and the permeability increases.

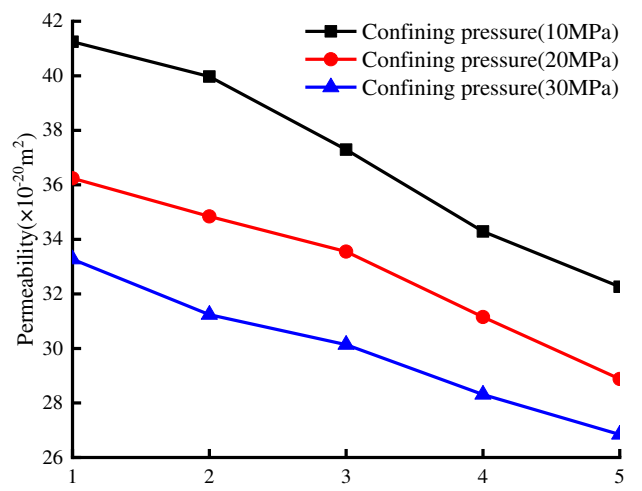

$P_{1}-P_{2}(\mathrm{MPa})$

(a)

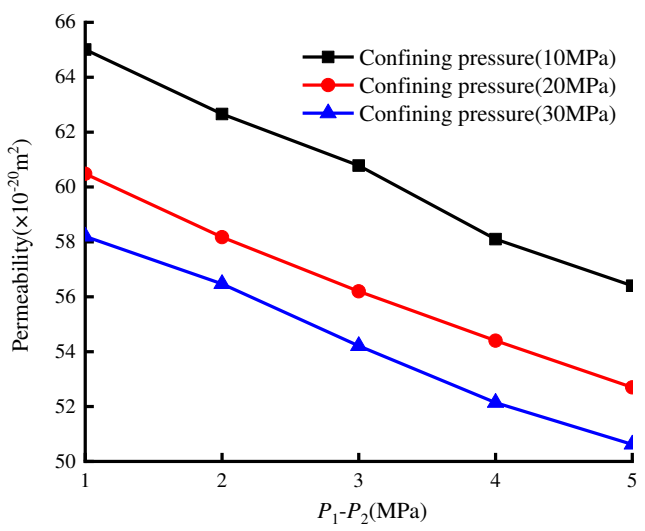

(c)

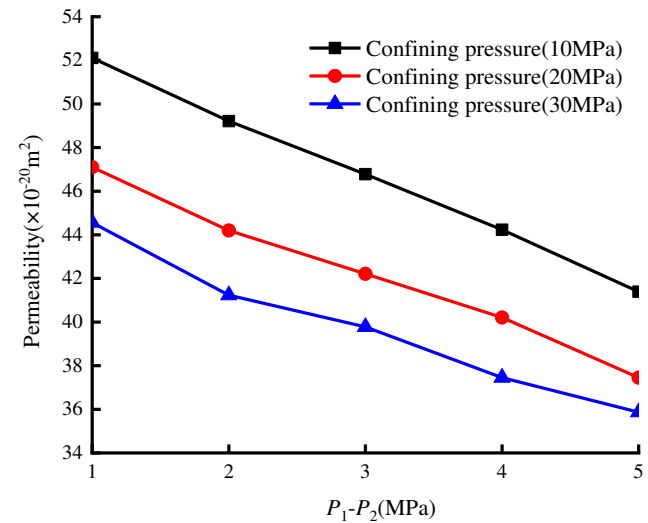

(b)

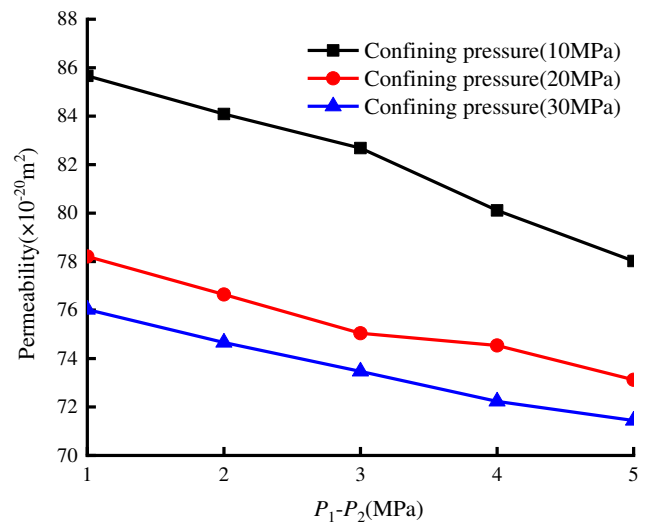

(d)

Fig. 6. The relationship curve between permeability and seepage pressure difference under different confining pressures

At present, many scholars have studied the influence of confining pressure on permeability in the process of rock seepage. Tan et al. (2019) found the change characteristics of the permeability of the rock mass during the increase of confining pressure and found that the permeability decreases in a negative exponential law with the increase of stress. This paper analyzes the relationship curve between permeability and confining pressure under 
different temperature effects and different osmotic pressure differences. As shown in Fig. 7, as the confining pressure gradient increases, the permeability decreases, and the trend becomes slower. After non-linear fitting of the test data, it is found that the permeability of the sandstone samples under different osmotic pressure differences after the action of each temperature follows the relationship of the power exponential function $y=a x^{b}$. And the average degree of fit $R^{2}$ of each fitting result is greater than 0.95 . It shows that the degree of the fitting is good, and it can be used to study the influence of confining pressure on permeability under different temperature effects and different osmotic pressure differences.

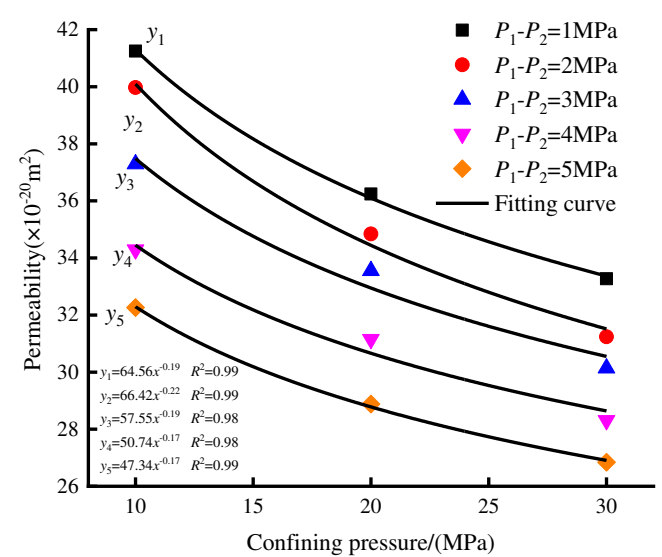

(a)

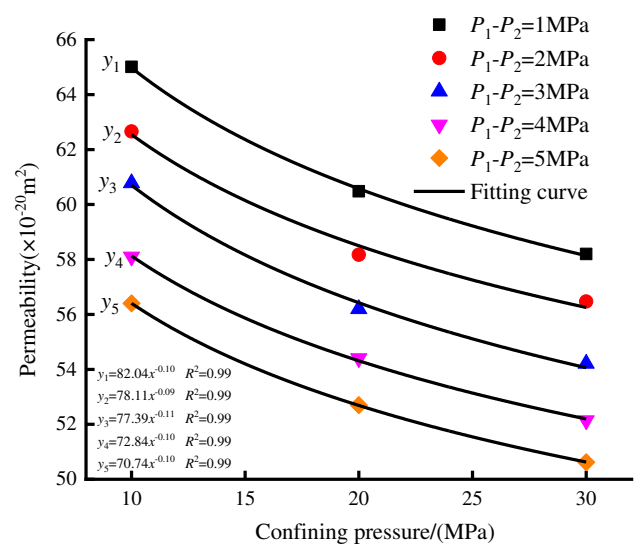

(c)

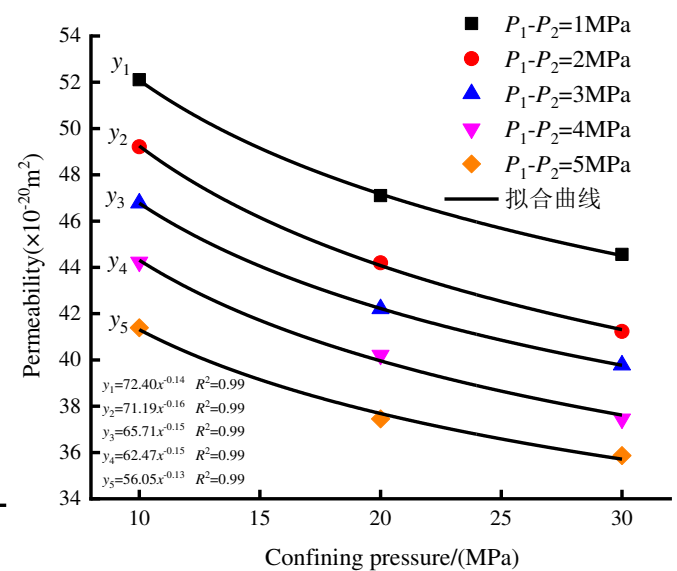

(b)

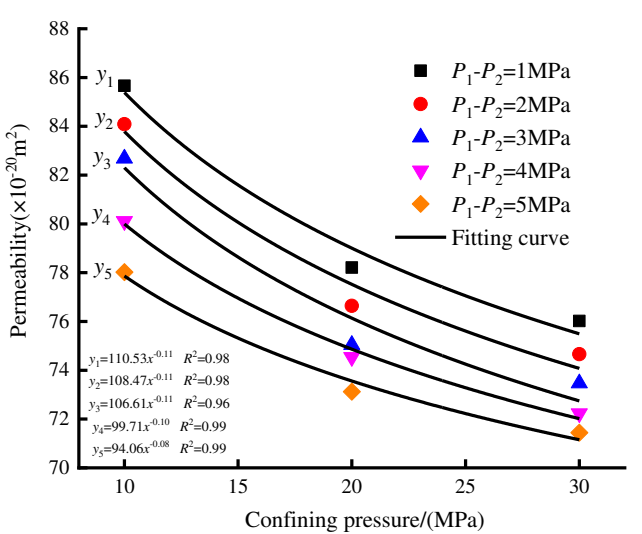

(d)

Fig. 7. The relationship between permeability and confining pressure under different seepage pressure gradients

(a) $20^{\circ} \mathrm{C}$ (b) $50^{\circ} \mathrm{C}$

(c) $70^{\circ} \mathrm{C}$

(d) $90^{\circ} \mathrm{C}$

\subsubsection{Seepage characteristics of red sandstone under different temperatures}

Fig. 8 shows the change in the permeability of the red sandstone samples with temperature under different conditions of confining pressure and osmotic pressure difference. Permeability increased with increasing temperature. This suggests that a higher temperature facilitated the formation of seepage channels in the rock samples. The development of fractures is affected by temperature and progresses rapidly. With increasing temperature, therefore, seepage channels in the samples widened and increased, and permeability increased 

resistance of the pure water medium, thus decreasing the effective stress within the rock. High-temperature water has a dissolution and lubrication effect on mineral particles and reduces the interparticle cementation strength, thus rendering the rock softer and more ductile. Water and heat have a synergistic effect on the mechanical degradation of the rock at the micro-level. The axial stress loading transforms this micro-degradation of the rock to macro-destruction.

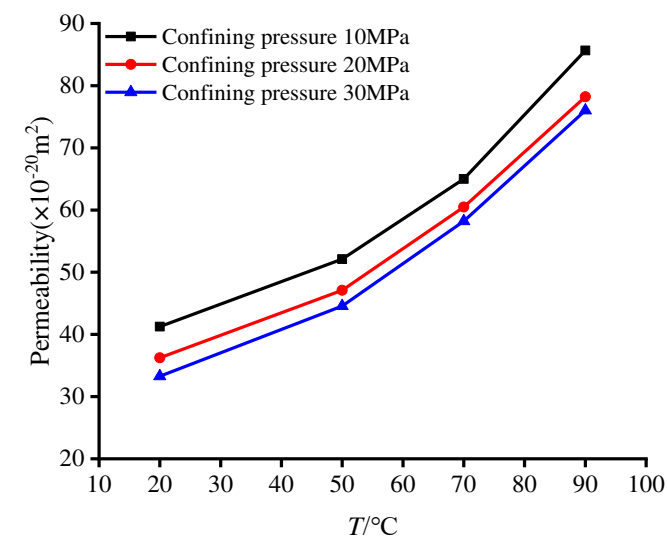

(a)

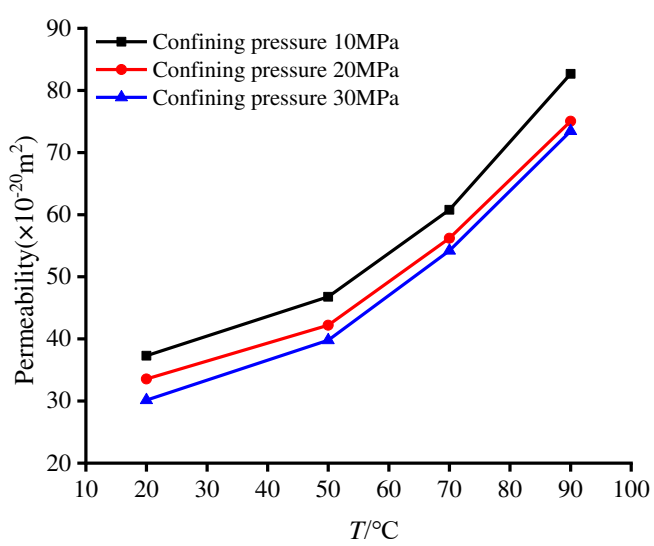

(c)

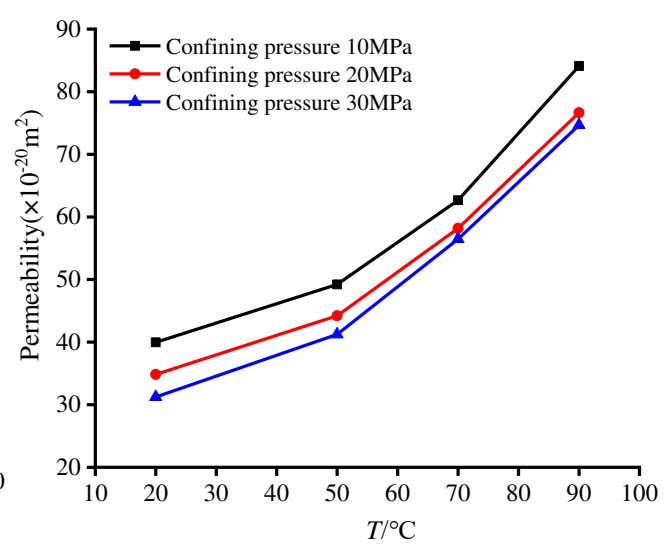

(b)

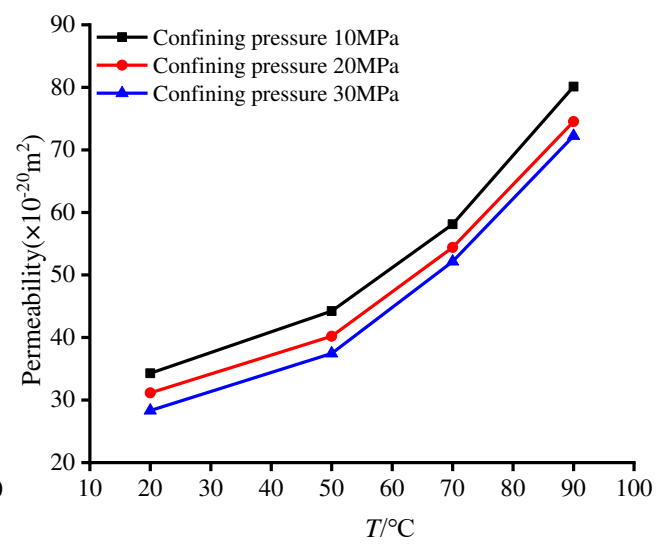

(d)

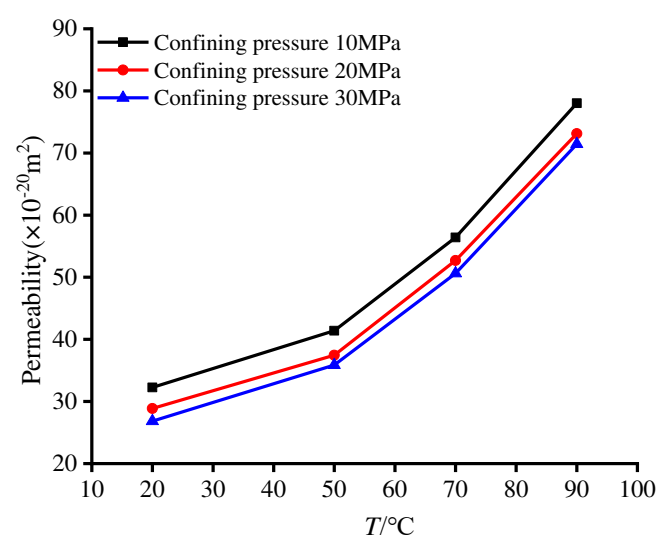

(e)

Fig. 8. Permeability evolution of red sandstone under different temperatures

(a) $\Delta P=1 \mathrm{MPa}$ (b) $\Delta P=2 \mathrm{MPa}$ (c) $\Delta P=3 \mathrm{MPa}$ (d) $\Delta P=4 \mathrm{MPa}$ (e) $\Delta P=5 \mathrm{MPa}$ 
4 The constitutive model of rock statistical damage considering the interaction of thermal and osmotic pressure

\subsection{Model building}

In order to reflect the stress-strain process of rock under the coupled action of high temperature and seepage, it is very important to establish a damage constitutive model considering the combined action of osmotic pressure and high temperature.

When the temperature is high, a large number of microscopic cracks will inevitably occur in the rock, and gradually expand with the increase of temperature, resulting in a significant decrease in the elastic modulus (Xu et al. 2018). Therefore, the definition of thermal damage $\left(D_{\mathrm{T}}\right)$ in this article focuses on the effect of temperature on the mechanical properties of rocks, which can be expressed as:

$$
D_{T}=1-\frac{E_{T}}{E_{0}}
$$

Where $E_{\mathrm{T}}$ is the modulus of elasticity under temperature $T . E_{0}$ is the modulus of elasticity at room temperature $\left(20^{\circ} \mathrm{C}\right)$.

Under the action of high temperature, the particles of rock material are not uniform and the distribution is relatively random. At the same time, the rock micro-element body contains a large number of micro-cracks and fissures, and its strength value also changes randomly. This paper assumes that the strength of the rock micro-element body under the action of high temperature obeys the Weibull density function, which can be expressed as:

$$
f(x)=\frac{m}{K}\left(\frac{x}{K}\right)^{m-1} \exp \left[-\left(\frac{x}{K}\right)^{m}\right]
$$

Where $x$ is the intensity value of the infinitesimal body. $m$ and $K$ are the parameters of the Weibull distribution function that affect the shape and size of the rock element. They are directly affected by temperature. Therefore, this paper introduces formula (8) to consider the influence of temperature on the statistical constitutive model of rock damage. The Weibull parameter of the rock under different temperature is:

$$
\left\{\begin{array}{l}
m_{T}=m_{0}\left(1-D_{T}\right) \\
K_{T}=K_{0}\left(1-D_{T}\right)
\end{array}\right.
$$

Where $m_{0}$ and $K_{0}$ are the Weibull parameters of the rock at $20^{\circ} \mathrm{C}$, respectively. $m_{T}$ and $K_{T}$ are the Weibull parameters of the rock under the action of different temperature $T$ respectively.

Under the action of load, the original micro-cracks inside the rock expand and evolve, resulting in continuous damage to the rock. Therefore, the continuous damage variable $D$ can be expressed as: 


$$
D=\frac{N_{F}}{N}=\frac{N \int_{0}^{f\left(\sigma_{i j}^{\prime}\right)} f\left(\sigma_{i j}^{\prime}\right) d \sigma_{i j}^{\prime}}{N}=\int_{0}^{f\left(\sigma_{i j}^{\prime}\right)} f\left(\sigma_{i j}^{\prime}\right) d \sigma_{i j}^{\prime}=1-\exp \left[-\left(\frac{f\left(\sigma_{i j}^{\prime}\right)}{K_{T}}\right)^{m_{T}}\right]
$$

Where $N_{\mathrm{F}}$ is the number of rock micro-elements that fail under a certain stress state under high temperature. $N$ is the total number of rock micro-elements. $f\left(\sigma_{i j}^{\prime}\right)$ is the infinitesimal body strength.

In the framework of the elastic theory of porous media, Biot (1941) corrected the effective stress principle for the seepage problem, and obtained:

$$
\sigma_{i j}^{\prime}=\sigma_{i j}-b \Delta P \delta_{i j}
$$

Where $\sigma_{i j}$ is the stress tensor. $\sigma_{i j}^{\prime}$ is the effective stress tensor. $\Delta P$ is the osmotic pressure difference. $\delta_{i j}$ is the unit second-order tensor and $\delta_{i j}=1(i=j)$, otherwise $\delta_{i j}=0(i \neq j) . b$ is the Biot coefficient, and the value range is $0 \sim 1$. For the convenience of research, take $b=1$.

According to the Lemaitre strain equivalence principle and the effective stress concept (Lemaitre 1984), the strain produced by the rock under the stress condition (nominal stress) measured in the test is equal to the effective strain produced by the damaged rock under the effective stress condition. Due to the influence of friction and confining pressure of the rock specimen, the internal micro-element body still has the ability to transmit compressive and shear stress after failure, and there is a certain residual strength. Therefore, the damage correction coefficient $\eta$ is introduced, where $0<\eta<1$. Therefore, this paper establishes the rock damage constitutive relationship as:

$$
\sigma_{i}^{*}=\frac{\sigma_{i}}{1-\eta D} \quad(i=1,2,3)
$$

According to formula (10) and formula (11), the effective stress tensor under stress-seepage action can be obtained as:

$$
\sigma_{i j}^{* \cdot}=\frac{\sigma_{i j}-\Delta P \delta_{i j}}{1-\eta D}
$$

Where $\delta_{i j}=1$. At the same time, Hong et al. (2014) believe that the rock stress-strain under high temperature has an obvious elastic stage, so according to the generalized Hooke's law, the axial stress-strain relationship can be obtained:

$$
\varepsilon_{1}=\frac{1}{E}\left[\sigma_{1}^{* \prime}-\mu\left(\sigma_{2}^{* \prime}+\sigma_{3}^{* \prime}\right)\right]
$$

In the conventional triaxial test of rock, $\sigma_{1}>\sigma_{2}=\sigma_{3}$. Substituting equation (12) into equation (13), the axial stress-strain relationship under the action of osmotic pressure is obtained: 


$$
\sigma_{1}=E \varepsilon_{1}(1-\eta D)+2 \mu \sigma_{3}+(1-2 \mu) \Delta P
$$

In the process of rock uniaxial and triaxial tests, when the temperature increases, the internal friction angle of the rock gradually increases, otherwise the cohesion will decrease. And the M-C strength criterion has the characteristics of simple parameters, easier calculation, and suitable for rock analysis (Lemaitre 1984). Therefore, this paper adopts the M-C strength criterion to describe the strength of rock micro-elements, and the expression is:

$$
f\left(\sigma_{i j}^{\prime}\right)=\sigma_{1}^{* \prime}-\sigma_{3}^{* \prime}-\left(\sigma_{1}^{* \prime}+\sigma_{3}^{* \prime}\right) \sin \phi_{T}
$$

Where $\phi_{T}$ is the internal friction angle of the rock under different temperatures.

Combining formula (12) and formula (14), formula (15) is transformed into:

$$
f\left(\sigma_{i j}^{\prime}\right)=\frac{\sigma_{1} \varepsilon_{1 t} E-\sigma_{3} \varepsilon_{1 t} E-\sin \phi_{T}\left(\sigma_{1} \varepsilon_{1 t} E+\sigma_{3} \varepsilon_{1 t} E\right)}{\sigma_{1}-2 \mu \sigma_{3}+(2 \mu-1) p_{w}}
$$

The axial deviator stress $\sigma_{1 t}$ recorded in the triaxial seepage test is actually the difference between the axial stress $\sigma_{1}$ and the confining pressure $\sigma_{3}$, namely:

$$
\sigma_{1 t}=\sigma_{1}-\sigma_{3}
$$

During the test, the confining pressure and pore water pressure are first loaded before the bias pressure. Therefore, the existing initial strain $\varepsilon_{0}$ is:

$$
\varepsilon_{0}=\frac{1-2 \mu}{E}\left(\sigma_{3}-\Delta P\right)
$$

The $\varepsilon_{1 t}$ in the micro-element body strength $f\left(\sigma_{i j}^{\prime}\right)$ is the sum of the experimentally measured strain value $\varepsilon_{1}$ and the initial strain $\varepsilon_{0}$, namely:

$$
\varepsilon_{1 t}=\varepsilon_{1}+\varepsilon_{0}
$$

Substituting formula (17) and formula (19) into formula (16), namely:

$$
f\left(\sigma_{i j}^{\prime}\right)=\frac{\left[(1-2 \mu)\left(\sigma_{3}-\Delta P\right)+E \varepsilon_{1}\right]\left(\sigma_{1 t}-\sigma_{1 t} \sin \phi_{T}-2 \sigma_{3} \sin \phi_{T}\right)}{\sigma_{1 t}+(1-2 \mu)\left(\sigma_{3}-\Delta P\right)}
$$

According to formula (14) and formulas (17) (20), a statistical damage constitutive model of rock considering the interaction of high temperature and osmotic pressure under triaxial conditions can be obtained:

$$
\sigma_{1 t}=\left[(1-2 \mu)\left(\sigma_{3}-\Delta P\right)+E \varepsilon_{1}\right]\left[1-\eta+\eta \exp \left[-\left(\frac{f\left(\sigma_{i j}^{\prime}\right)}{K_{T}}\right)^{m_{T}}\right]\right]+(2 \mu-1)\left(\sigma_{3}-\Delta P\right)
$$

\subsection{Determination of model parameters}

The parameters that need to be determined in the model are $m_{T}$ and $K_{T}$. The peak stress and peak strain of the 
rock are different under the combined action of confining pressure, osmotic pressure, and temperature (Martin et al. 1994). At the same time, the model parameters $m_{T}$ and $K_{T}$ are also closely related to the operating temperature. In this paper, the linear fitting method is used to obtain the model parameters. Equation (21) can be transformed into:

$$
\frac{\frac{\sigma_{1 t}-(2 \mu-1)\left(\sigma_{3}-\Delta P\right)}{\left[(1-2 \mu)\left(\sigma_{3}-\Delta P\right)+E \varepsilon_{1}\right]}+\eta-1}{\eta}=\exp \left[-\left(\frac{f\left(\sigma_{i j}^{\prime}\right)}{K_{T}}\right)^{m_{T}}\right]
$$

After taking two logarithms on both sides of the equation and simplifying it, we can get:

$$
Y=m_{T} X-B
$$

Where:

$$
X=\ln f\left(\sigma_{i j}^{\prime}\right)
$$

$$
Y=\ln \left\{\ln \left[\frac{\eta}{\frac{\sigma_{1 t}-(2 \mu-1)\left(\sigma_{3}-\Delta P\right)}{\left[(1-2 \mu)\left(\sigma_{3}-\Delta P\right)+E \varepsilon_{1}\right]}+\eta-1}\right]\right\}
$$

$$
B=m_{T} \ln K_{T}
$$

The $m_{T}$ and $B$ values can be obtained by linear fitting through the test data, and then the $\mathrm{K}_{T}$ can be obtained as:

$$
K_{T}=\exp \left(\frac{B}{m_{T}}\right)
$$

\subsection{Model validation}

To verify the applicability of the model developed in this study, the full stress-strain curves of the red sandstone samples under a confining pressure of $30 \mathrm{MPa}$ and an osmotic pressure difference $(\Delta P)$ of $5 \mathrm{MPa}$, at 20 , 50, 70, and $90^{\circ} \mathrm{C}$ were selected. After processing the experimental data, the Poisson's ratio of the samples at 20 , 50,70 , and $90^{\circ} \mathrm{C}$ was $0.24,0.24,0.23$, and 0.24 , respectively, and the internal friction angle was $45,42,40$, and $39^{\circ}$, respectively. After fitting the experimental data, the value of $\eta$ was 0.98 . The calculated model parameters are presented in Table 2. The theoretical curves of the full stress-strain relationship in red sandstone under different temperatures according to the constitutive model were obtained and compared with the experimental curves (Fig. 9). The theoretical value of statistical rock damage predicted by the constitutive model developed in this study was close to the experimental value, and fully reflected the experimental trend in the post-peak stage. The model achieved an accurate prediction of the stress-strain relationship in red sandstone under high temperature and 
osmotic pressure conditions. This confirmed the applicability of the constitutive model.

\begin{tabular}{cccccccc}
\multicolumn{7}{c}{ Table 2 Model parameters } \\
\hline $\mathrm{T} /{ }^{\circ} \mathrm{C}$ & $\Delta \mathrm{P} / \mathrm{MPa}$ & $\mu$ & $\varphi_{\mathrm{T}}{ }^{\circ}$ & $\sigma_{3} / \mathrm{MPa}$ & $E / \mathrm{GPa}$ & $\mathrm{m}_{\mathrm{T}}$ & $\mathrm{K}_{\mathrm{T}} / 10^{6}$ \\
\hline 20 & 5 & 0.24 & 45 & 30 & 35.94 & 5.02 & 1.36 \\
50 & 5 & 0.24 & 42 & 30 & 30.35 & 7.85 & 1.86 \\
70 & 5 & 0.23 & 40 & 30 & 26.74 & 9.45 & 2.11 \\
90 & 5 & 0.24 & 39 & 30 & 20.93 & 11.45 & 1.87 \\
\hline
\end{tabular}

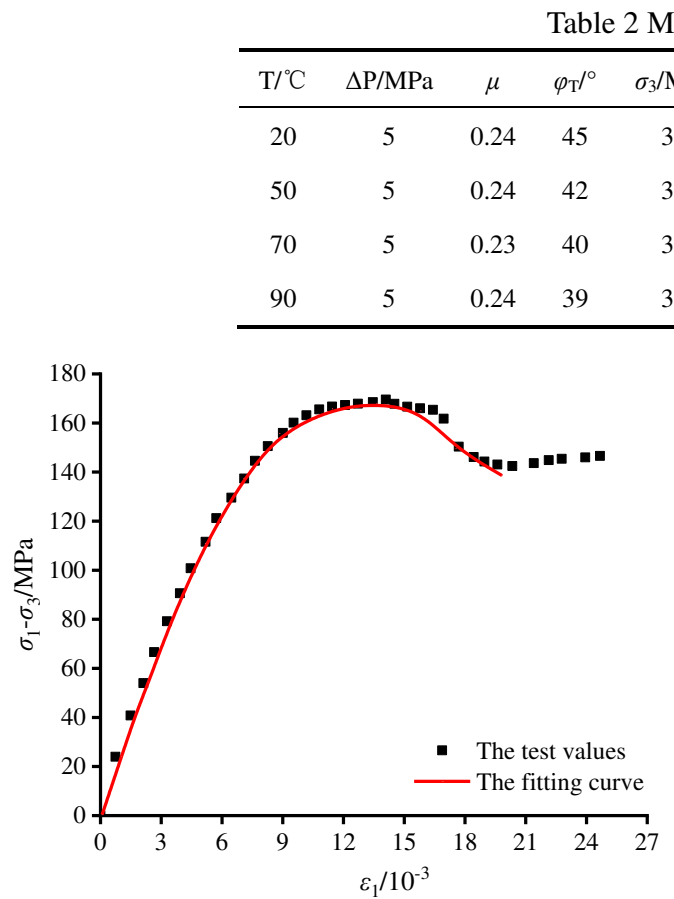

(a)

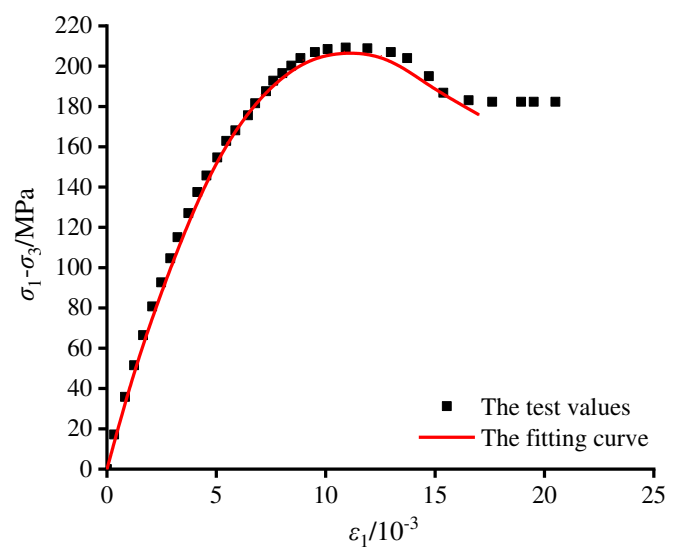

(c)

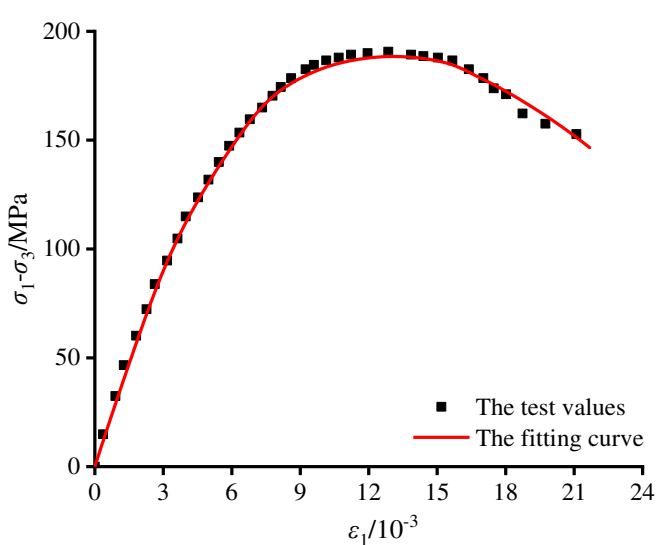

(b)

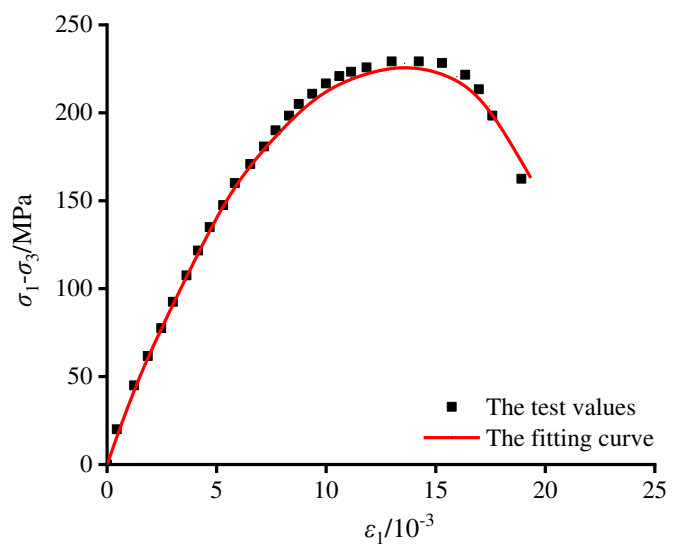

(d)

Fig. 9. Comparison of test value and the theoretical curve

5 Discussions

\subsection{Evolution of the Weibull distribution parameters with temperatures}

To study the influence of temperature on the Weibull distribution parameters $m_{T}$ and $K_{T}$, the constitutive equation was used to obtain the relationship between $m_{T}, K_{T}$, and temperature (Table 2, Fig. 10). With increasing temperature, $m_{T}$ gradually increased, while $K_{T}$ gradually increased, and then decreased. This is because $m_{T}$ reflects not only the shape of the rock microelements but also the plastic properties of the rock. With increasing temperature plasticity increased, and the relative elasticity decreased. The $K_{T}$ value determines the peak rock strength and is affected by the discrete characteristics of the rock sample: the larger the $K_{T}$ value, the smaller the 
macroscopic strength of the rock. At $90{ }^{\circ} \mathrm{C}, K_{T}$ decreased. This is consistent with the law that, under thermal-mechanical coupling, the strength of the rock decreases with increasing temperature.

488

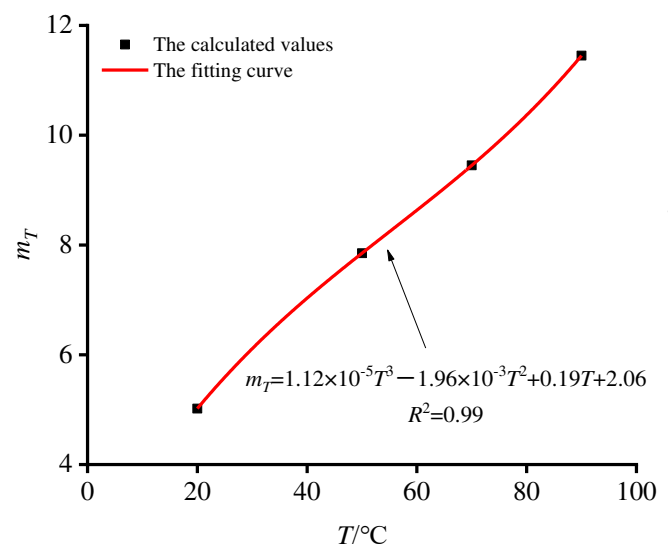

(a)

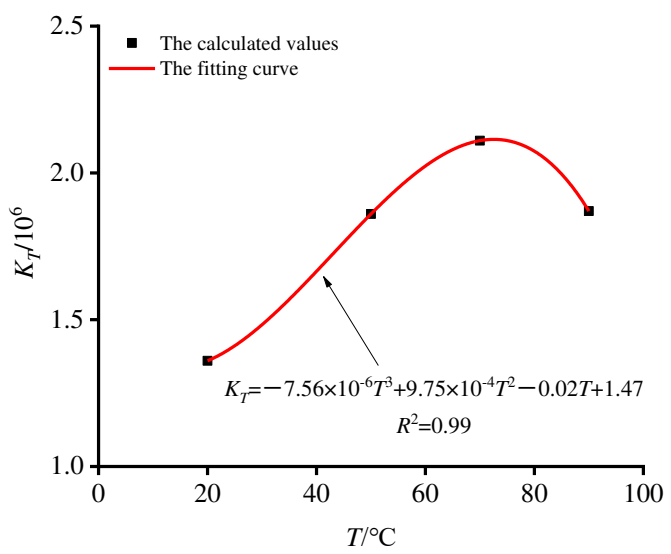

(b)

Fig. 10. $m_{T}$ and $K_{T}$ change with temperature

\subsection{Permeability evolution characteristics of internal thermal damage in rock samples}

To study the correlation between permeability, $k$, and rock damage at high temperatures in more detail, we focused on the test data at 50,70 , and $90{ }^{\circ} \mathrm{C}$. High temperature changes not only the rock's elastic modulus but also the viscosity coefficient of seepage water, which affects permeability. In this study, therefore, we selected the thermal damage, $D_{\mathrm{T}}$, as a measure of the degree of damage (damage index). The $D_{\mathrm{T}}$ can be calculated according to Equation (6).

The fitting calculation to the permeability obtained by the transient method, as shown in Fig. 11, obtains the expression of permeability $k$ and damage degree $D_{\mathrm{T}}$ :

$$
k=\eta_{0} \xi \exp \left(a+b D_{T}+c D_{T}^{2}\right)
$$

Where $k$ is permeability. $\xi$ is the order of magnitude of permeability $\left(10^{-20} \mathrm{~m}^{2}\right) . D_{\mathrm{T}}$ is thermal damage and damage index. a, b, and c are fitting parameters, which are obtained by experiments. $\eta_{0}$ is the dynamic viscosity coefficient $\left(\mathrm{cm}^{2} / \mathrm{s}\right)$ of water under the action of $50^{\circ} \mathrm{C}, 70^{\circ} \mathrm{C}$ and $90^{\circ} \mathrm{C}$, which can be obtained according to the empirical formula:

$$
\eta_{0}=0.01775 /\left(1+0.0337 T+0.000221 T^{2}\right)
$$

Where $T$ is the temperature of the water.

We verified the applicability of the fitting formula at 50, 70, and $90^{\circ} \mathrm{C}$ (Fig. 11). From Fig. 11, it can be seen that the relationship between permeability and thermal damage $\left(D_{\mathrm{T}}\right)$ was exponential, and that the correlation coefficient $\mathrm{R}^{2}$ was 0.99 . The evolution law of permeability, suggesting that permeability increases with the degree of damage, can thus be obtained from this relationship. In addition, the results further confirm that the thermal 

progressive fracturing of red sandstone under thermal-mechanical coupling. This further supports the conclusion that, in red sandstone, permeability increases with temperature, as discussed in Section 3.2.2.

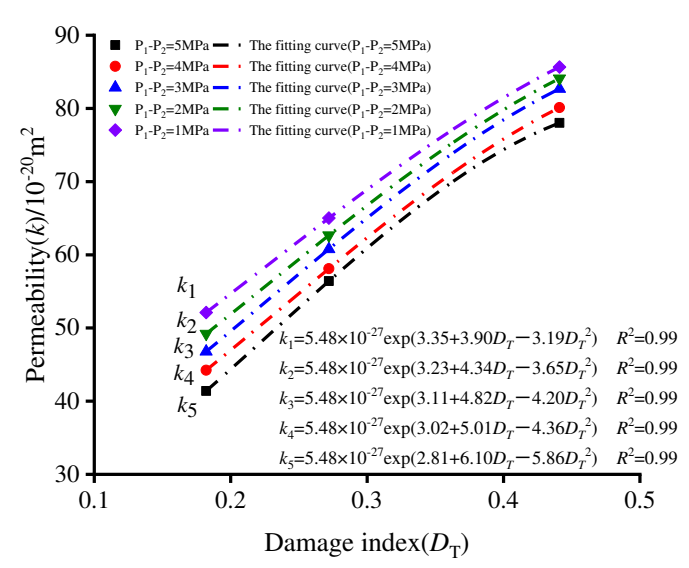

(a)

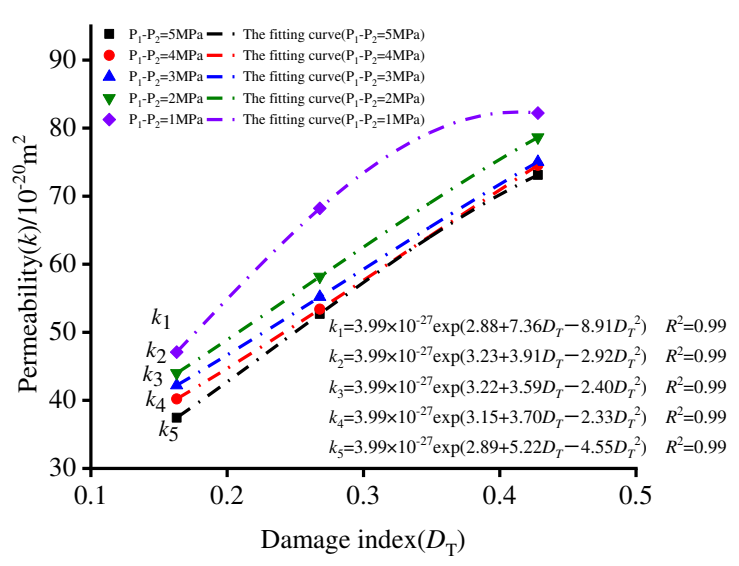

(b)

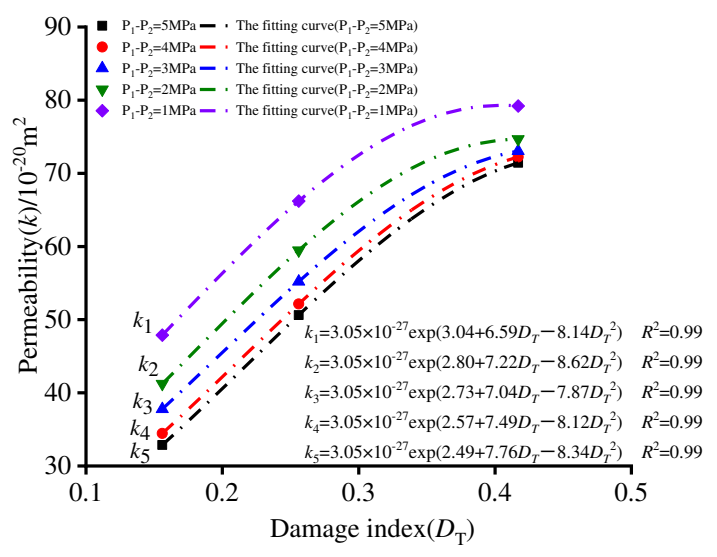

(c)

Fig. 11. Correlation characteristics of permeability $k$ and damage index $D_{T}$ under different confining pressure and osmotic pressure difference (a) confining pressure 10MPa (b) confining pressure 20MPa (c) confining pressure $30 \mathrm{MPa}$

\section{Conclusions}

We conducted an experimental study of the seepage characteristics of red sandstone across the entire stress-strain process, under different conditions of temperature, osmotic pressure difference, and confining pressure, and analyzed the results of these experiments. To simulate the stress-strain process in the rock under the coupled effects of high temperature and seepage, we also developed a constitutive model of statistical rock damage that considers the combined effects of osmotic pressure and high temperature. Based on the experimental results and the constitutive model, we discussed the evolution of thermal damage-induced permeability. Our main conclusions are as follows:

(1) In red sandstone under the same conditions of confining pressure and osmotic pressure difference, with increasing temperature ductility increased, the plastic flow became more prominent, residual stress appeared, the 
elastic modulus of the rock increased, and the permeability in each stage of the deformation process also increased.

(2) As the confining pressure gradient increased, permeability decreased, but at a progressively slower rate. At the same time, the development of fractures was affected by temperature: the higher the operating temperature, the easier the production of seepage channels within the rock. With increasing temperature, therefore, the seepage channels widened and increased, and permeability increased significantly.

(3) The theoretical value calculated by the constitutive model of statistical rock damage that accounts for the combined effect of high temperature and osmotic pressure, developed in this study, is close to the experimental value. The model developed in this study fully reflects the evolution of permeability in the post-peak stage, and adequately describes the stress-strain relationship in red sandstone under high temperature and osmotic pressure.

(4) The relationship between permeability and the thermal damage index $\left(D_{\mathrm{T}}\right)$ is exponential, with a correlation coefficient $\mathrm{R}^{2}$ of 0.99 . This confirms that the thermal damage index can characterize the degree of rock damage. It also reveals the mechanism of permeability evolution in red sandstone, where damage increases due to progressive fracturing under thermal-mechanical coupling.

\section{Acknowledgments}

The authors are thankful for these supports and reviewers for their valuable comments to improve this manuscript.

\section{Funding Information}

This work was supported by the National Natural Science Foundation of China (No. 52078093, 51678101), the Liao Ning Revitalization Talents Program (No. XLYC1905015).

\section{Conflict of interest}

On behalf of all authors, the corresponding author states that there is no conflict of interest.

\section{References}

Biot MA (1941) General theory of three-dimensional consolidation. J Appl Phys 12:155-164

Brace WF, Waish JB, Frangos WT (1968) Permeability of granite under high pressure. J Geophs Res 73(6):2225-2236

Chaki S, Takarli M, Agbodjan WP (2008) Influence of thermal damage on physical properties of a granite rock: porosity, permeability and ultrasonic wave evolutions. Constr Build Mater 22(7):1456-1461

Chen SW, Yang CH, Wang GB (2017b) Evolution of thermal damage and permeability of Beishan granite. Appl Therm Eng 110:1533-1542

Chen ZQ, Yang ZM, Wang MR (2018b) Hydro-mechanical coupled mechanisms of hydraulic fracture propagation in rocks with cemented natural fractures. J Pet Sci Eng 163:421-434

Chen YF, Hu SH, Kai W (2014) Experimental characterization and micromechanical modeling of damage-induced permeability 
variation in Beishan granite. Int J Rock Mech Min Sci 71:64-76

Eberhardt E, Stead D, Stimpson B, Read RS (1998) Identifying crack initiation and propagation thresholds in brittle rock. Can Geotech J 35(2):222-233

Gräf V, Jamek M, Rohatsch A, Tschegg E (2013) Effects of thermalheating cycle treatment on thermal expansion behavior of different building stones. Int J Rock Mech Min Sci 64:228-235

Heiland J (2003) Permeability of triaxially compressed sandstone: influence of deformation and strain-rate on Permeability. Pure Appl Geophys 160:889-908

He LX, Yin Q, Jing HW (2018) Laboratory investigation of granite permeability after high-temperature exposure. Processes 6(4)

Hong T, ZIEGLER M, KEMPKA T (2014) Physical and mechanical behavior of claystone exposed to temperatures up to $1000^{\circ} \mathrm{C}$. Int J Rock Mech Min Sci 70:144-153

Lemaitre J (1984) How to use damage mechanics. Nuclear Engineering and Design. 80(3):233-245

Li ZW, Feng XT, Zhang YJ, Zhang C, Xu TF, Wang YS (2017) Experimental research on the convection heat transfer characteristics of distilled water in manmade smooth and rough rock fractures. Energy 133:206-218

Liu E, Huang R, He S (2012b) Effects of frequency on the dynamic properties of intact rock samples subjected to cyclic loading under confining pressure conditions. Rock Mech Rock Eng 45 (1):89-102

Martin CD, Chandler NA (1994) The progressive fracture of Lac du Bonnet granite. Int J Rock Mech Min Sci \& Geomech Abstr 31(6):643-659

Meng T, Liu RC, Meng XX (2019) Evolution of the permeability and pore structure of transversely isotropic calcareous sediments subjected to triaxial pressure and high temperature. Eng Geol 253:27-35

Oda M, Takemura T, Aoki T (2002) Damage growth and permeability change in triaxial compression tests of Inada granite. Mech Mater 34 (6):313-331

Ranjith PG, Viete DR, Chen BJ, Perera MS (2012) Transformation plasticity and the effect of temperature on the mechanical behaviour of Hawkesbury sandstone at atmospheric pressure. Eng Geol 151:120-127

Rostovanyi Porta M (2013) Thermo-Hydro-Mechanical analysis of a Callovo-Oxfordian clay. Barcelona: Universitat Politècnica de Catalunya. School of Civil Engineering.

Schulze O, Popp T, Kern H (2001) Development of damage and permeability in deforming rock salt. Eng Geol 61:163-180

Shao S, Ranjith PG, Wasantha PLP, Chen BK (2015) Experimental and numerical studies on the mechanical behaviour of Australian Strathbogie granite at high temperatures: an application to geothermal energy. Geothermics 54:96-108

Sun Q, Zhang Y (2019) Combined effects of salt, cyclic wetting and drying cycles on the physical and mechanical properties of sandstone. Eng Geol 248:70-79 
Tan X, Konietzky H (2019) Numerical simulation of permeability evolution during progressive failure of Aue granite at the grain scale level. Comput Geotech 112: 185-196

Tanikawa W, Tadai O, Mukoyoshi H (2015) Permeability changes in simulated granite faults during and after frictional sliding. Geofluids 14(4): 481-494

Walch A, Mohajeri N, Gudmundsson A, Scartezzini JL (2021) Quantifying the technical geothermal potential from shallow borehole heat exchangers at regional scale. Renew Energ, 165(P1):369-380

Wang HL, Xu WY, Shao JF (2014) Experimental researches on hydro-mechanical properties of altered rock under confining pressures. Rock Mech Rock Eng 47:485-493

Wang L, Liu JF, Pei JL (2015) Mechanical and permeability characteristics of rock under hydro-mechanical coupling conditions. Environ Earth Sci 73:5987-5996

Wang SG, Elsworth D, Liu JS (2013) Permeability evolution during progressive deformation of intact coal and implications for instability in underground coal seams. Int J Rock Mech Min Sci 58:34-45

Xiao WJ, Zhang D, Wang XJ, Yang H, Wang XL, Wang CY (2020) Research on microscopic fracture morphology and damage constitutive model of red sandstone under seepage pressure. Nat Resour Res 29(5):3335-3350

Xie HP, Peng SP, Jiang YD (2005) Study on rock mechanics in deep mining engineering. Chinese Journal of Rock Mechanics and Engineering, 24(16):2803-2813. (in Chinese)

Xu XL, Murat Karakus, Gao F, Zhang ZZ (2018) Thermal damage constitutive model for rock considering damage threshold and residual strength. J Cent South Univ 25(10)

Yang SQ, Huang YH, Jiao YY (2015) An experimental study on seepage behavior of sandstone material with different gas pressures. Acta Mech Sinica 31:837-844

Yang SQ, Tian WL, Elsworth D, Wang JG, Fan LF (2019) An Experimental study of effect of high temperature on the permeability evolution and failure response of granite under triaxial compression. Rock Mech Rock Eng 53(10):4403-4427

Yang SQ, Xu P, Li YB, Huang YH (2017) Experimental investigation on triaxial mechanical and permeability behavior of sandstone after exposure to different high temperature treatments. Geothermics 69(5):93-109

Yao C, Jiang QH, Shao JF (2015) A numerical analysis of permeability evolution in rocks with multiple fractures. Transp Porous Media 108 (2): 289-311

Yin WT, Zhao YS, Feng ZJ (2020) Experimental research on the permeability of fractured-subsequently-filled granite under high temperature-high pressure and the application to HDR geothermal mining. Renew Energ 153: 499-508.

Zhao Y, Feng Z, Zhao Y, Wan Z (2017) Experimental investigation on thermal cracking, permeability under HTHP and application for geothermal mining of HDR. Energy 132:305-314 
621 Zhao, ZH (2016) Thermal influence on mechanics properties of granite: a microcracking perspective. Rock Mech Rock Eng 49:747-762

623 Zhang CH, You S, Ji HG, F Li, Wang HT (2019) Hydraulic properties and energy dissipation of deep hard rock under h-m coupling and cycling loads. Thermal Science 23(S3):S935-S942

625 Zhu TT, Jing HW, Su HJ, Yin Q, Du MR, Han GS (2016) Physical and mechanical properties of sandstone containing a single fissure after exposure to high temperatures. Int J Min Sci Technol 26 (2):319-325 